\title{
Developing a Model with Ergonomic Aspects Using Endurance Time and Rest Allowance for Supporting the Optimization of Production Line Material Supply: A Case of Single-Operator Multi-Materials
}

\author{
Sezen Korkulu $\mathbb{D D}^{1}{ }^{1}$ Krisztián Bóna $\mathbb{D}^{1},{ }^{1}$ and Tamás Péter $\mathbb{D}^{2}$ \\ ${ }^{1}$ Department of Material Handling and Logistics Systems, Budapest University of Technology and Economics, Budapest, Hungary \\ ${ }^{2}$ Department of Transport and Vehicle Management, Budapest University of Technology and Economics, Budapest, Hungary \\ Correspondence should be addressed to Sezen Korkulu; sezen.korkulu@logisztika.bme.hu
}

Received 26 March 2021; Revised 30 July 2021; Accepted 11 August 2021; Published 29 August 2021

Academic Editor: Vahid Kayvanfar

Copyright ( 92021 Sezen Korkulu et al. This is an open access article distributed under the Creative Commons Attribution License, which permits unrestricted use, distribution, and reproduction in any medium, provided the original work is properly cited.

\begin{abstract}
Various studies on the issues regarding economic and environmental sustainability in inventory management have been investigated by many researchers in recent years. However, the integration of ergonomics as an aspect of social sustainability in an inventory model is still scarce. This paper presents an extension of ergonomic inventory modeling with a new mathematical model which integrates relaxation allowance and endurance time to the ergonomic inventory model. The rest allowance is determined by endurance time, contraction time, and relative force based on several items such as weight, and it helps to prevent ergonomic risks and fatigue of the back muscles. The model has been analyzed in a numerical work based on our specific simulator and parameteric analysis to present validness in different scenarios. Consequently, our results show that optimization with ergonomics in production line material supply provides notable advantages as it increases overall productivity.
\end{abstract}

\section{Introduction}

Inventory management and lot sizing are critical problems for many industries. The primary focus of the problems is economic sustainability. Especially, the supply of the production lines, the service time, and the availability of the materials are the most critical factors which may cause several problems. Fast service and continuous availability are the most common terms used in the production process to determine the aims of the main functions for optimization problems. In every case, the operators at the line must be able to reach the necessary materials for production. Otherwise, the production line may be stopped, and consequently, there may be a considerable cost and an impracticable problem. This problem can be handled by holding a lot of stocks at the lines, but this is not an economically sustainable solution as the specific cost of the reserved production area will be expensive. The other solution can be to supply the production lines with higher frequency and to hold a lower level of stocks at the lines. In this case, the total cost of the operations will increase. Many researchers have examined these problems extensively by beginning with the Economic Order Quantity (EOQ) model developed by Harris [1]. The EOQ and lot-sizing models have been studied and extended by many researchers in accordance with economic (time-varying demand, inflation, shortages, and backlogging), environmental $\left(\mathrm{CO}_{2}\right.$ emission and environmental cost), and social (human rights, fair labour practices, living conditions, health, and safety) sustainability aspects [2]. Especially, the researchers have focused on the environmental and economic sustainability aspects. However, the social sustainability aspect has been neglected in inventory management, and there are very few studies focused on the social dimension of sustainability $[3,4]$. Although there are many studies regarding the environmental and economic sustainability of inventory 
models, according to Kazemi et al. [5], there are few exceptions which investigate ergonomics as a social sustainability aspect [6-19]. Even though there are studies that integrate ergonomic aspects in inventory management, there is a lack of studies that investigate the maximum endurance time, rest allowance, and production line supply with multimaterials. It is necessary to integrate social sustainability in inventory management to optimize the decision-making process and performance. Ergonomics is an important component of the decision-making process in inventory management and lot sizing. Furthermore, ergonomics is necessary for the prevention of repetitive strain injuries and work-related musculoskeletal disorders, which may cause a long-term disability. Work-related musculoskeletal disorders (WRMDs) are the most common occupational disorders, such as sprains, strains, soreness, back disorders, pain, and carpal tunnel syndrome. Especially, work-related back disorders are associated with repetitive motion, sustained postures, excessive force, the weight of object lifted, high static muscle load, high force exertion on the hands and wrists, sudden application of force, inadequate rest or recovery periods, localized mechanical stresses to tissues, and poor spinal support [20]. We suppose that the causes are preventable with an ergonomic lot sizing in the material handling, which has an important impact on the inventories at the production lines. The official statistical reports show that there is a link between manual material handling and WRMDs. In accordance with the report issued by OSHA [21], 30\% of European workers suffer from back pain, which is one of the most common work-related musculoskeletal disorders, and awkward postures, as well as lifting and handling loads, are the most common reasons. According to Driscoll et al. [22], low back pain as an occupational disability affects almost $26 \%$ of the world's population. The report issued by the European Agency for Safety and Health at Work has emphasized that work-related musculoskeletal disorders are one of the most important reasons for workrelated mortality in EU-28 (14.66\%) and in the world (14.96\%) [23]. It leads to the total cost of work-related musculoskeletal disorders up to 2\% of GDP in Europe [24].

In parallel with the purpose of this paper, the questions to be considered are as follows:

(1) How to integrate maximum endurance time and rest allowance in the calculation of optimal lot sizes for the production line supply with multi-materials to prevent ergonomic risks?

(2) What is the difference between optimal solution and nonoptimal solution after the integration of the ergonomic aspects?

(3) How do different parameters (height of placement, unit weight, and distance of movement) affect the optimal solution?

This study aims to contribute a new model which extends the ergonomics studies in inventory management $[10,13]$ and integrates ergonomic aspects using endurance time and rest allowance for supporting the optimization of production line material supply of multi-materials. This paper integrates, for the first time, the maximum endurance time and rest allowance formulas $[25,26]$ in a lot-sizing model as an ergonomic measure. The rest allowance prevents disorders associated with manual material handling works in the production supply process that includes picking, storing, and pushing motions. The model determines the optimal lot sizes for multi-materials. The optimal lot size represents the load value which allows workers to work continuously without the need for rest allowance, and consequently, the total cost is minimized. The lot size values higher than the optimal lot size values mean that workers need to rest to prevent any ergonomic disorders and that there may be a rest time cost as they do not work during the rest. The total cost consists of rest time cost, holding cost, and material handling cost. The optimal solution of the model is based on the minimization of both economic and ergonomic costs. The main innovations considered in this study can be summarized as follows. A new modeling approach, which integrates endurance time and rest allowance to support the multi-objective optimization of the production line material supply process for single operator and multi-materials, has been developed, and a numerical study and parameteric analysis have been conducted to investigate the opportunities of the proposed model. Furthermore, the rest allowance [25] and maximum endurance time [26] formulations are linearized.

This paper has been structured as follows. The following section will present a literature review on sustainable inventory management and ergonomic measures. In Section 3, the problem will be examined in detail, and necessary assumptions will be explained. In Section 4, the mathematical formulation of the lot-sizing model developed will be shown with ergonomic aspects based on single operator and multimaterials. In Section 5, the results of a numerical example and parameteric analysis will be presented, and Section 6 will include the conclusion of the paper.

\section{Literature Review}

Sustainable inventory management and lot sizing aim to reduce social and environmental effects of an industry without affecting profitability [27]. There are many studies focused on the environmental and economic aspects of sustainability of inventories. Taft [28] has extended the EOQ model with continuous consumption and periodic production and has developed the Economic Production Quantity (EPQ) model. Wagner and Whitin [29] developed the Dynamic Economic Lot (DEL) model where the demand rate is supposed to be changing over a set number of periods. The EOQ model has also been extended for shortages, deterioration of items, payment delays, and growing items [30-33]. Especially, the environmental and economic sustainability aspects of inventory management have been studied. Inventory models have been developed with various economic aspects, such as imperfect production cost [34-36], incremental discounts [37, 38], and transportation cost [39-41]. The environmental sustainability aspect embodies an extensive investigation on $\mathrm{CO}_{2}$ emission and green emission [5, 27, 42-47]. For instance, an EPQ model with an 
environmental quality index, which considers economic and environmental aspects, was developed by Glock et al. [48]. Furthermore, an EOQ model, which considers $\mathrm{CO}_{2}$ emission as an environmental cost, was developed by Wahab et al. [49].

In the literature, there are many studies on inventory models regarding economic and environmental sustainability aspects [34, 40, 42-45]. However, there are only a few contributions regarding human health and ergonomic aspects as social sustainability aspects [50].

The ability of a muscle to maintain its function over a period of time with multiple contractions is endurance [51]. The maximum endurance time of the muscles is an important indicator for measuring muscular fatigue to prevent work-related musculoskeletal disorders. Many researchers have conducted several studies on endurance time. Rohmert [25] developed a general endurance time model for all muscle groups with a limit of $15 \%$ relative force, which means that, under this value, workers can continue to work without any fatigue. Monod and Scherrer [52] focused on the notions of maximum work and maximum time of work to define the critical power of muscular work. In addition, they developed an endurance time model for static, dynamic, and intermittent static work to define the maximum amount of work that can be performed in a specific time as well as the circumstances of work performed without fatigue. Sato et al. [53] investigated the relationship between the force level of isometric contractions and endurance time on the elbow flexors, shoulder abductors, and knee extensors. Rohmert [54] developed endurance time models for muscle groups, such as shoulder, elbow, trunk, and hand. Sjogaard [55] investigated endurance time and intramuscular changes during long-term contractions. The author has found that rest periods are needed for the recovery of muscles even after low-load muscular work. The relationship between endurance time and relative force for the static pull and static torque was investigated by Manenica [56]. Rose et al. [57] investigated endurance time in fully flexed postures. They found that the fully flexed postures may be assessed by more general prediction models for endurance. In addition, energy expenditure is one of the other ergonomic measurement methods used to estimate the required energy to complete a manual task from oxygen consumption [58]. The Ovako Working Posture Assessment System (OWAS), which analyzes working postures, has identified 72 different postures [59]. The NIOSH lifting equation, which assesses the ergonomic risks, has been used to evaluate lifting and lowering tasks [60]. The maximum endurance time has been defined as a key parameter to prevent muscle fatigue [61]. The maximum endurance time models have primarily investigated different muscle groups, such as elbow, hand, and shoulder or postures. As the aim of this study is to examine the load on the spine, various endurance time studies, which examine the muscle groups of the elbow, hand, and shoulder as well as different postures, are not suitable for our research. For this reason, the general endurance model developed by Rohmert [25] has been used in this study as it is suitable for all muscle groups and postures.
Table 1 shows the sustainable inventory models with ergonomic aspects in the literature. We have tried to summarize the main contributions based on the "number of objectives," such as the "bi-objective" $(A)$ and the "multiobjective" $(B)$ aspects, and other important "ergonomic aspects," such as the application of "human energy expenditure" $(C)$, the "rest allowance" $(D)$, the "energy expenditure rate based on Predetermined Motion Energy System" $(E)$, the "lifting index" $(F)$, the "vibration exposure" $(G)$, the "OCRA (the occupational repetitive actions)" $(H)$, the "maximum endurance time" $(I)$, the "environmental ergonomics" $(J)$, the "assembly system design with ergonomics" $(K)$, and, last but not least, the "human availability" $(L)$.

Battini et al. [8] analyzed the relationship between ergonomics and assembly system design techniques. They examined ergonomics in designing the assembly system and found that the design of the assembly system and ergonomics should complete each other for assessment of time efficiency in modern industries. In addition, they did not consider the maximum endurance time and rest allowance for assessment of the ergonomic risks. Battini et al. [10] developed a new measurement technique with consideration of energy expenditure equations [58] and rest allowance formulation [26]. Their method allows us to simplify the ergonomic assessment of each assembly task. Furthermore, they did not consider the determination of the optimal lot size and did not cover the multi-material supply. Battini et al. [9] developed various functions which are considered warehouse picking activities with the human availability and the rest allowance. They found that an improvement in ergonomic conditions has a positive impact on the total cost of the system. Their model did not cover motions other than picking associated with the WRMDs, and it did not consider the lot size. Battini et al. [11] developed a new multi-objective model for assembly line balancing, which includes energy expenditure rate based on the Predetermined Motion Energy System (PMES), and their model did not consider the lot size and multi-material supply. Battini et al. [12] developed a mixed-integer model which integrates assembly line balancing and parts feeding by incorporating ergonomic aspects based on rest allowance formulas of Garg et al. [58] and Price [62]. Their model did not consider the lot size and multi-material supply. Andriolo et al. [7] developed a lotsizing model that considers multi-objective optimization of ergonomic aspects based on a lifting index (LI). Their model aims to minimize both cost and ergonomic risks, and it did not consider the rest allowance concept but instead used Pareto frontiers. In addition, their model is bi-objective, and they did not consider different motions which cause WRMDs and multi-material supply. Battini et al. [13] developed a mathematical model which investigates picking and storing motions with the energy expenditure rate for rest time assessment. Their ergonomic lot size model is based on the rest allowance formulation developed by Price [62]. Their model did not consider the multi-material supply. In addition, they have not considered motions other than picking and storing, which cause the WRMDs. Botti et al. [14] developed a mathematical model to design lean processes with ergonomics for hybrid assembly lines. They did not consider the lot size and manual material handling motions that cause WRMDs. Finco et al. [15] 
TABLE 1: Sustainable inventory models with ergonomic aspects in the literature.

\begin{tabular}{|c|c|c|c|c|c|c|c|c|c|c|c|c|}
\hline \multirow[t]{2}{*}{ Studies } & \multicolumn{2}{|c|}{$\begin{array}{c}\text { Number } \\
\text { of } \\
\text { objectives }\end{array}$} & \multirow[b]{2}{*}{$C$} & \multirow[b]{2}{*}{$D$} & \multirow[b]{2}{*}{$E$} & \multirow[b]{2}{*}{$F$} & \multicolumn{3}{|c|}{ rgonomic aspects } & \multirow[b]{2}{*}{$J$} & \multirow[b]{2}{*}{ K } & \multirow{2}{*}{$L$} \\
\hline & $A$ & $B$ & & & & & $G$ & $H$ & $I$ & & & \\
\hline Battini et al. [8] & - & & & & & & & & & & 0 & \\
\hline Battini et al. [9] & $\bullet$ & & & & & & & & & & & $\bullet$ \\
\hline Battini et al. [10] & • & & & • & & & & & & & & $\bullet$ \\
\hline Battini et al. [11] & & $\bullet$ & & & $\bullet$ & & & & & & & \\
\hline Andriolo et al. [7] & & • & & & & • & & & & & & \\
\hline Battini et al. [12] & - & & 0 & 0 & & & & & & & & \\
\hline Battini et al. [13] & & $\bullet$ & $\bullet$ & $\bullet$ & & & & & & & & \\
\hline Botti et al. [14] & 0 & & & & & & & ○ & & & 0 & \\
\hline Zadjafar and Gholamian [18] & - & & & & & & & & & - & & \\
\hline Finco et al. [15] & - & & $\bullet$ & 0 & & & & & & & & \\
\hline Finco et al. [16] & $\bullet$ & & & & & & $\bullet$ & & & & $\bullet$ & \\
\hline Al-Araidah et al. [6] & - & & $\bullet$ & & & & & & & & & \\
\hline Finco et al. [17] & $\bullet$ & & $\bullet$ & - & $\bullet$ & & & & & & & \\
\hline Zhang et al. [19] & & $\bullet$ & & & & & & ○ & & & & \\
\hline This study & & $\bullet$ & & ○ & & & & & $\bullet$ & & & \\
\hline
\end{tabular}

developed three heuristic methods that consider energy expenditure and rest allowance for assembly balancing problems. In addition, their model did not cover the determination of the lot size. Zadjafar and Gholamian [18] developed a mathematical model that considers environmental ergonomics and environmental pollution to minimize both cost and environmental pollution. Finco et al. [16] developed a bi-objective model that considers vibration exposure to eliminate ergonomic risks in assembly line design. Their model did not cover the multi-material supply and the determination of the optimal lot size. Al-Araidah et al. [6] developed a Monte Carlo simulation to estimate fatigue allowance [62] with the integration of energy expenditure formulas of Garg et al. [58] for female order pickers. Their study did not cover the manual material handling motions other than picking and did not consider the optimal lot size. Finco et al. [17] developed a mathematical model that integrates human energy expenditure as an ergonomic aspect in assembly line balancing problems with the smoothness index. However, they have did not consider the lot size and multi-material supply. Zhang et al. [19] developed a multi-objective mathematical model that integrates the OCRA method to eliminate the ergonomic risks for U-shaped assembly lines, and their model did not consider the determination of the optimal lot size.

As can be seen in Table 1, the research gap can be described as follows. Many kinds of research have focused on human energy expenditure as an ergonomic aspect of socially sustainable inventory management, but the maximum endurance time as an ergonomic measure has not been studied. Moreover, the issue of handling multi-materials in the production line material supply with ergonomic measures has not been investigated. Then again, pushing motion has been neglected in previous studies of sustainable inventory models which integrate ergonomic aspects. There are no previous studies on sustainable inventory models considering the maximum endurance time as an ergonomic measure and multi-material handling of production line material supply. There is a gap in the literature regarding studies that consider maximum endurance time and rest allowance, multi-material production material supply, and motions such as pushing or pulling as ergonomic aspects in the modeling. Furthermore, most of the inventory models apply special costs to the operations for refilling the inventory system with materials. Such refilling activities, especially for the supply of the production lines, are carried out in connection with the human workforce. However, the relevant activity carried out contains only the cost factors and does not contain the effects of ergonomic factors for the human workforce. Therefore, this paper presents the extension of the ergonomics studies in inventory management $[10,13]$ and the development of a new model for the determination of the lot sizes in material handling, especially in the case of the line supply with ergonomic aspects, to close this research gap. For the first time, the maximum endurance time has been integrated into a sustainable inventory model as an ergonomic measure. According to the literature, there is a lack of studies that consider pushing motions and multi-material production line supply. For this reason, the developed single-operator-multi-material inventory model considers rest allowance, maximum endurance time functions developed by Rohmert $[25,26]$, and picking, storing, and pushing motions for preventing work-related back disorders and ergonomic risks and supports economic and social sustainability.

\section{Problem Description}

3.1. A Framework for the Investigated Material Handling Process. The problem studied in this paper is a case of a production line supply process modeled as a so-called "single-operator-multi-material" system. The model covers transportation of " $M$ " number of raw materials from a 
supermarket to a dedicated production line on the production area and transportation of " $E$ " number of empties from this production line to the supermarket through manual material handling with a simple cart by a logistics operator. The investigated production environment has been given as a concrete layout that determines the place of the supermarket, the place of the dedicated production line, and the path between these two components of the layout. The physical process of the line supply will contain the picking, storing, and pushing activities for manual handling of the aforementioned raw materials and empties. Figure 1 shows the production layout investigated, and Figure 2 illustrates the "single-operator-multi-material" job cycle as a decomposition of the mentioned activities.

The job cycle consists of ten steps; the first step is picking the materials from the supermarket $\left(h^{\mathrm{pis} s}\right)$, the second step is storing the materials in the cart from the supermarket $\left(h^{\mathrm{st}, c}\right)$, the third step is pushing the cart from the supermarket to the production area $\left(d_{s, p}\right)$, the fourth step is picking the materials from the cart in the production area $\left(h^{\mathrm{p} i, c}\right)$, the fifth step is storing the materials to the production line in the production area $\left(h^{\text {st, } p}\right)$, the sixth step is picking the empties from the production line in the production area $\left(h^{\mathrm{pi}, p}\right)$, the seventh step is storing the empties in the cart in the production area $\left(h^{\text {st, } c}\right)$, the eighth step is pushing the cart from the production area to the supermarket $\left(d_{s, p}\right)$, the ninth step is picking the empties from the cart $\left(h^{\mathrm{p}, \mathrm{c}}\right)$, and the tenth step is storing the empties to the supermarket $\left(h^{\text {st,s }}\right)$ and resting. The double-sided arrows represent the height of placement and distance parameters applied by us to the AIM tables to determine the time necessities of the operations in the job cycle (see Section 4.1).

The notations of the realized heights and distances during the material handling process in the model, which describe the physical topology, are given in Table 2.

3.2. Objectives, Assumptions, and Notations. The objectives of this study are as follows:

(1) To develop a new lot-sizing model for the production line supply operation in a "single-operator-multimaterial" case based on rest allowance and endurance time formulations developed by Rohmert $[25,26]$ to integrate the ergonomic aspects in the calculation of the optimal lot size.

(2) To investigate the outcomes with different scenarios of endurance time and rest allowance on the lot sizes and the total cost of production line supply operation.

The following assumptions are made for developing the new model:

(1) The model considers one logistics operator to handle the materials in the line supplying process.

(2) The model considers the handling of " $M$ " types of raw materials between the supermarket and the production line. For this reason, based on this assumption and the previous one, we name this model variation as a multi-material-single-operator model (referred to as the MMSO).

(3) In all material handling activities, empties of the same kind (i.e., boxes) have been used to handle the raw materials.

(4) A simple cart is used for transportation of the raw materials and empties between the loading points with a pushing motion.

(5) The aforementioned line supplying process is a cyclical activity during the operation of the production line. The count of the necessary line supplying transactions will strongly depend on the material needs and the availability time of the raw materials on the production line. Therefore, all of the related costs will also strongly depend on the operational properties of the line supply.

(6) The developed model is a discrete-event-based model, and it investigates the actual values of the parameters in all of the " $t$ " time slots. It means that if the start of a line supplying transaction is necessary for an investigated " $t$ " time slot considering the actual availability rules of the raw materials in the production line, then based on the decomposition of the process (see Figure 2), all of the time necessities and the related cost components will be calculated.

The following notations are used throughout the paper (Table 3).

\section{The Methods and the Mathematical Model}

4.1. The AIM Methodology. The AIM ("Anyagmozgatási Időszükséglet Meghatározás"; in English, "Determination of Material Handling Time Requirements") tables were developed by Hungarian researchers at the Budapest University of Technology and Economics in the middle of the 1960s. The AIM tables are used to determine the time necessity of material handling systems operating periodically. The objectives of the AIM are to define the time necessity of a weight forwarding process, to determine how many machines, tools, and workers the system needs, to plan the schedule for tasks, and to analyze the working efficiency of existing systems [63]. The method allows for the planning of the material handling systems by hand without any tools and of the material handling systems by hand with tools and forklifts. Therefore, we apply the AIM method to estimate the material handling time necessities. The time estimation procedure used in the AIM method is very similar to the well-known MTM (Methods-Time Measurement) method; however, the AIM method has been specialized for logistics activities. The AIM method calculation parameters for the production line supply are shown in Figure 3 where the " $h$ " parameters are the average levels of the picking and storing logistics units from and to the logistics equipment, and the " $d$ " parameters refer to the estimated average length of the realized motions.

Additionally, we need to give the weight of the handled logistics units to be determined by the weight of the 


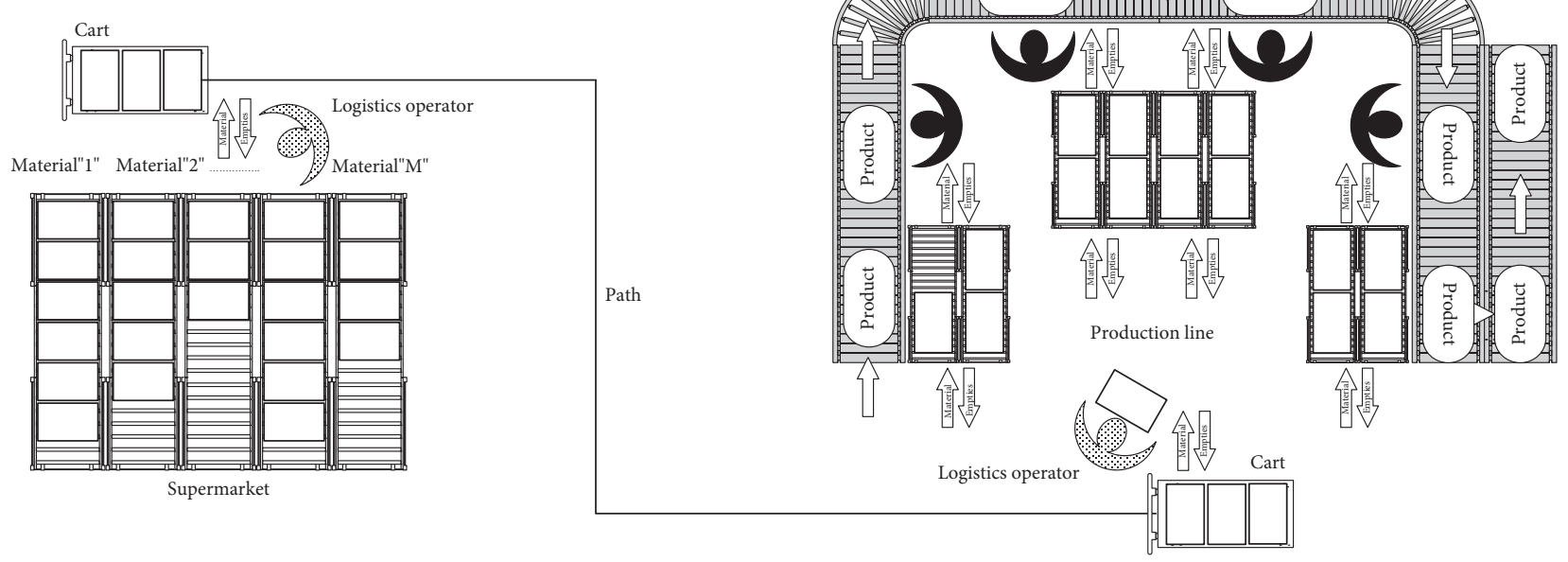

FIGURE 1: The production layout of investigated cycle.

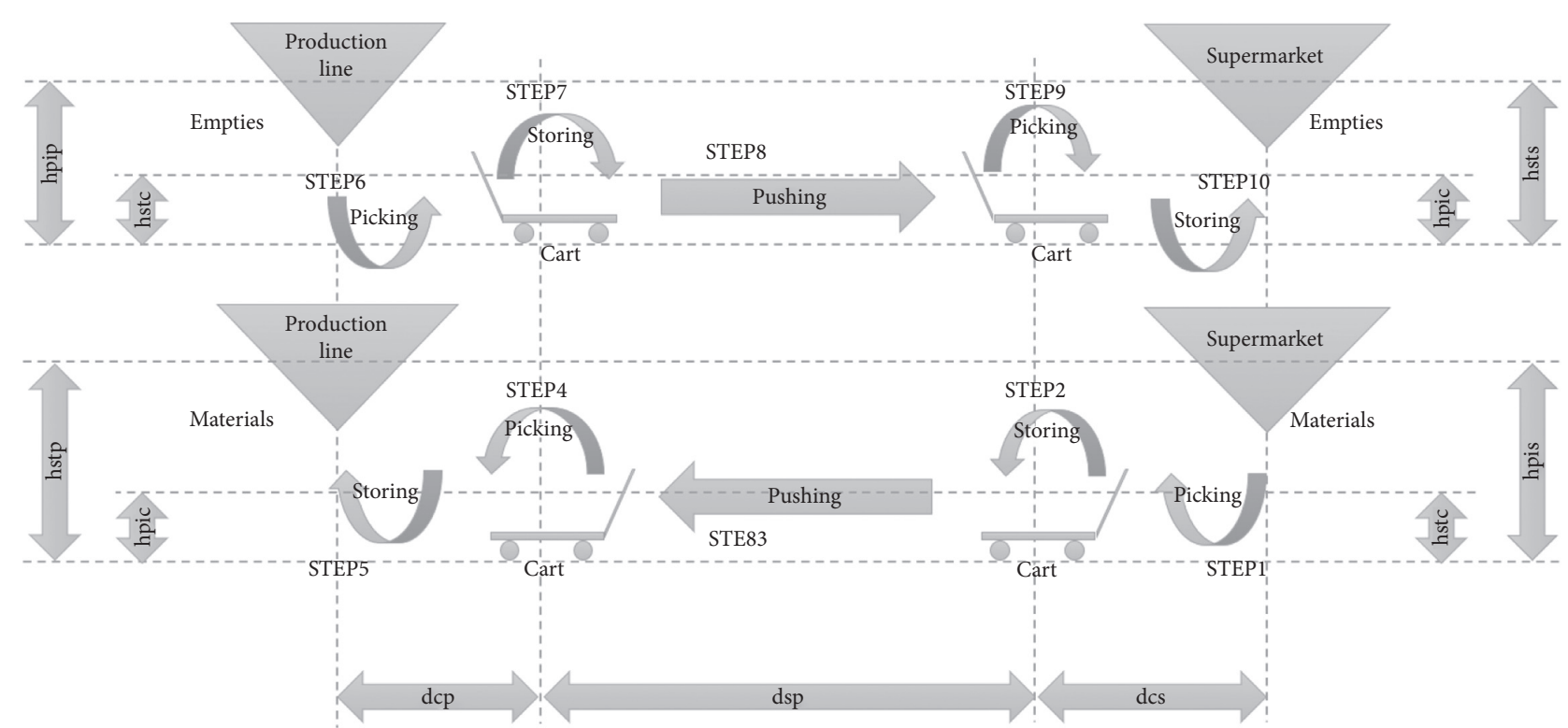

FIgURE 2: Decomposition of the complex material handling activity investigated and the heights and distances applied in the model.

materials handled and the empty units applied. Furthermore, the weight of the logistics units handled may also depend on the lot sizes used indirectly. Based on these parameters, we can estimate the time necessities of the operations (see Appendix A).

4.2. Rest Allowance and Endurance Time. An excessive load on the spinal muscles affects neuromuscular spinal stability as it may cause muscle fatigue, musculoskeletal disorders, and low back pain [52]. The neuromuscular spinal stability is affected by vibration and repetitive loading $[65,66]$. To reduce ergonomic risks, we calculate the rest time and maximum endurance time of the operator in accordance with the equation developed by
TABLE 2: The notations of heights and distances of the material handling process.

\begin{tabular}{|c|c|}
\hline Symbols & Definition \\
\hline$h^{\mathrm{st}, p}$ & $\begin{array}{c}\text { Height of placement of the production line for } \\
\text { storing }(\mathrm{m})\end{array}$ \\
\hline$d_{c, p}$ & Distance between the cart and the production line $(\mathrm{m})$ \\
\hline$d_{s, p}$ & $\begin{array}{c}\text { Distance between the supermarket and the production } \\
\text { line }(\mathrm{m})\end{array}$ \\
\hline$h^{\mathrm{pi}, c}$ & Height of placement of the cart for picking (m) \\
\hline$h^{\mathrm{pi}, s}$ & Height of placement of the supermarket for picking $(\mathrm{m})$ \\
\hline$d_{c, s}$ & Distance between the cart and the supermarket (m) \\
\hline$h^{\mathrm{st \textrm {st } , \mathrm { c }}}$ & Height of placement of the cart for storing (m) \\
\hline$h^{\mathrm{pi}, p}$ & $\begin{array}{c}\text { Height of placement of the production line for } \\
\text { picking }(\mathrm{m})\end{array}$ \\
\hline$h^{\mathrm{st}, s}$ & Height of placement of the supermarket for storing $(\mathrm{m})$ \\
\hline
\end{tabular}


TABLE 3: Notations used in the mathematical model.

\begin{tabular}{|c|c|}
\hline Symbols & Definition \\
\hline $\mathrm{OT}_{t}$ & Operational time needed to be generated at a time slot " $t$ " $(\mathrm{min})$ \\
\hline $\mathrm{OT}_{\text {mat }, t}$ & Operational time needed for handling the material "mat" at a time slot " $t$ " (min) \\
\hline $\mathrm{OT}_{\mathrm{em}, t}$ & Total operational time needed for handling the empty "em" at a time slot " $t$ " (min) \\
\hline $\mathrm{OT}_{\mathrm{mat}, t}^{\mathrm{pl}, \mathrm{s}^{2}}$ & Operational time needed for picking the material "mat" from the supermarket at a time slot " $t$ " (min) \\
\hline $\mathrm{OT}_{\mathrm{mat}, t}^{\mathrm{st}, \mathrm{c}}$ & Operational time needed for storing the material "mat" to the cart at a time slot " $t$ " (min) \\
\hline $\mathrm{OT}_{\text {mat }, t}^{\mathrm{pu}}$ & Operational time needed for pushing the material "mat" to the production line at a time slot " $t$ " (min) \\
\hline $\mathrm{OT}_{\mathrm{mat}, t}^{\mathrm{p}, \mathrm{c}}$ & Operational time needed for picking the material "mat" from the cart at a time slot " $t$ " (min) \\
\hline $\mathrm{OT}_{\text {mat }, t}^{\text {st, } P, t}$ & Operational time needed for storing the material "mat" to the production line at a time slot " $t$ " (min) \\
\hline $\mathrm{OT}_{\mathrm{em}, t}^{\mathrm{pl}, p}$ & Operational time needed for picking the empty "em" from the production line at a time slot " $t$ " (min) \\
\hline $\mathrm{OT}_{\mathrm{em}, t}^{\mathrm{st}, \mathrm{c}}$ & Operational time needed for storing the empty "em" to the cart at a time slot " $t$ " (min) \\
\hline $\mathrm{OT}_{\mathrm{em}, t}^{\mathrm{pu}, t}$ & Operational time needed for pushing the empty "em" to the supermarket at a time slot " $t$ " (min) \\
\hline $\mathrm{OT}_{\mathrm{em}, t}^{\mathrm{p} 1, c}$ & Operational time needed for picking the empty "em" from the cart at a time slot " $t$ " (min) \\
\hline $\mathrm{OT}_{\mathrm{em}, t}^{\mathrm{st}, \mathrm{s}}$ & Operational time needed for storing the empty "em" to the supermarket at a time slot " $t$ " (min) \\
\hline$w_{\mathrm{ca}}$ & Weight of the cart $(\mathrm{kg})$ \\
\hline$w_{\text {mat }}$ & Weight of the material "mat" (kg/pcs) \\
\hline$w_{\mathrm{em}}$ & Weight of the empty “em" (kg/pcs) \\
\hline$w_{\text {mat }}^{\text {uni }}$ & Weight of the handled unit in case of material "mat" $(\mathrm{kg})$ \\
\hline$t_{\text {tact }}$ & Takt time of the production (min/product) \\
\hline$r_{\text {mat }}$ & The material requirement in the production line per product of material "mat" (pcs/product) \\
\hline$x_{\text {mat }, t}$ & Binary variable for the material "mat" at a time slot " $t$ " \\
\hline$q_{\text {mat }}$ & Lot size of the material "mat" (pcs) \\
\hline$x_{\mathrm{em}, t}$ & Binary variable for the empty "em" at a time slot " $t$ " \\
\hline$t_{\text {mat }}^{\mathrm{av}}$ & Availability of the material "mat" on the production line (min) \\
\hline$R_{\text {mat }}$ & The total material request of the production line in the examined time period (pcs) \\
\hline $\mathrm{RT}_{t}$ & Rest time needed to be generated at a time slot " $t$ " $(\min )$ \\
\hline $\mathrm{RT}_{\text {mat }, t}$ & Rest time needed for handling the material "mat" at a time slot " $t$ " (min) \\
\hline $\mathrm{RT}_{\mathrm{em}, t}$ & Rest time needed for handling the empty "em" at a time slot " $t$ " (min) \\
\hline $\mathrm{RT}_{\mathrm{m}}^{\mathrm{p} 1, \mathrm{~s}, t}, t$ & Rest time needed for picking the material "mat" from the supermarket at a time slot " $t$ " (min) \\
\hline $\mathrm{RT}_{\mathrm{m} \text { mat }, t}^{\mathrm{st}, \mathrm{c}}$ & Rest time needed for storing the material "mat" to the cart at a time slot " $t$ " (min) \\
\hline $\mathrm{RT}_{\mathrm{mat}, t}^{\mathrm{pu}}$ & Rest time needed for pushing the material "mat" to the production line at a time slot " $t$ " (min) \\
\hline 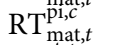 & Rest time needed for picking the material "mat" from the cart at a time slot " $t$ " (min) \\
\hline $\mathrm{RT}_{\text {mat }, t}^{\mathrm{s}, p}$ & Rest time needed for storing the material "mat" to the production line at a time slot " $t$ " (min) \\
\hline $\mathrm{RT}_{\mathrm{em}, t}^{\mathrm{pl}, p}$ & Rest time needed for picking the empty unit "em" from the production line at a time slot " $t$ " (min) \\
\hline $\mathrm{RT}_{\mathrm{em}, t}^{\mathrm{st}, \mathrm{c}, \mathrm{t}}$ & Rest time needed for storing the empty unit "em" to the cart at a time slot " $t$ " ( $\min )$ \\
\hline $\mathrm{RT}_{\mathrm{em}, t}^{\mathrm{pu}, t}$ & Rest time needed for pushing the empty unit "em" to the supermarket at a time slot " $t$ " (min) \\
\hline $\mathrm{RT}_{\mathrm{em}, t}^{\mathrm{pl}, t}$ & Rest time needed for picking the empty unit "em" from the cart at a time slot " $t$ " (min) \\
\hline $\mathrm{RT}_{\mathrm{em}, t}^{\mathrm{st}, s}$ & Rest time needed for storing the empty unit "em" to the supermarket at a time slot " $t$ " (min) \\
\hline $\mathrm{fMVC}_{\text {mat }}^{\text {uni }}$ & Relative force during the handling of one piece of unit load in case of material "mat" (\%) \\
\hline $\mathrm{fMVC}_{\mathrm{em}}$ & Relative force during the handling of one piece of empty load in case of empty "em" (\%) \\
\hline$F_{\max }^{\mathrm{pi} \& s t}$ & Maximum force load of the human spine for picking and storing $(\mathrm{N})$ \\
\hline$F_{\max }^{\max }$ & Maximum force load of the human spine for pushing $(\mathrm{N})$ \\
\hline$c_{w}$ & Unit worker wage $(\$ / \mathrm{h})$ \\
\hline$c_{h \text {, mat }}$ & Inventory holding cost $(\$ / \mathrm{pcs} / \mathrm{h})$ \\
\hline$C_{t}^{\mathrm{RT}}$ & Cost of the rest time at a time slot " $t$ " (\$) \\
\hline$C_{t}^{\mathrm{OP}}$ & Cost of the operation at a time slot " $t$ " (\$) \\
\hline$C^{\mathrm{OP}}$ & The total cost of the operation $(\$)$ \\
\hline$C^{\mathrm{HO}}$ & The total cost of the holding (\$) \\
\hline$C_{t}^{\mathrm{HO}}$ & Cost of the holding at a time slot " $t$ " $(\$)$ \\
\hline$C_{t}^{\mathrm{OT}}$ & Cost of the operation time at a time slot " $t$ " $(\$)$ \\
\hline$Q_{\text {mat }, t}$ & Closing stock of the material "mat" on the line at a time slot " $t$ " (pcs) \\
\hline & Total cost $(\$)$ \\
\hline
\end{tabular}

Rohmert $[25,26]$. The rest time and maximum endurance time equation developed by Rohmert $[25,26]$ can be defined as follows:

$$
\left.\mathrm{RT}=1800 \cdot\left(\frac{t}{T_{E}}\right)^{1.4} \cdot(\mathrm{fMVC}-0.15)\right)^{0.5}
$$

where "RT" is the rest time need if the contraction duration (working period of picking, storing, or pushing) is equal to " $t$ " expressed in minutes, and the " $T_{E}$ " endurance time can be defined as follows:

$$
T_{E}=-1.5+\frac{2.1}{\mathrm{fMVC}}-\frac{0.6}{\mathrm{fMVC}^{2}}+\frac{0.1}{\mathrm{fMVC}^{3}},
$$




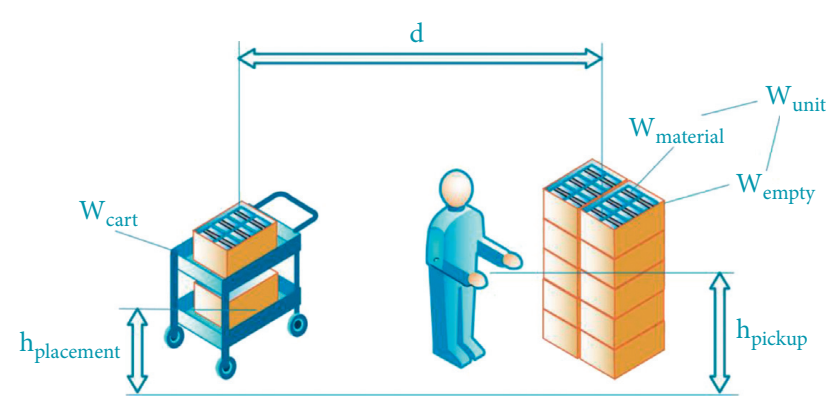

Figure 3: The parameters of the AIM method for the job cycle.

where $\mathrm{fMVC}=F_{\text {load }} / F_{\max }$ is the relative force, $F_{\text {load }}$ is the actual force load, and $F_{\max }$ is defined as the maximum force load of the human spine based on the applied limitations in the case of the investigated activity.

As given in Figure 4, the force load on the spine is calculated based on the determination of the balance of the body. $F 1$ represents the force load on the spine for picking and storing motions, and F3 represents the force load on the spine for pushing motion.

We use the maximum endurance time as an ergonomic measurement method that is a valuable method for the assessment of specific muscle areas, body parts, and postures. As we aim to decrease the work-related musculoskeletal disorders of the back, the maximum endurance time is suitable for the ergonomic measurement of our model. Other ergonomic measurement methods have some limitations, such as the energy expenditure known as a common method, and have considered the whole-body energy expenditure for the assessment. Furthermore, it may not be applicable to assess the workload on the spine muscles as well as the disorders of the back. The OWAS, which analyzes working postures based on 72 different postures, has a limitation as it does not consider any aspects of repetition or duration of the sequential postures. The NIOSH Lifting Equation, which helps to assess the ergonomic risks of lifting and lowering tasks, has a limitation on the other motions, such as pulling, pushing, and carrying. The force load of picking and storing can be calculated as follows:

$$
F_{\text {load }}^{\text {pi\&st }}=\frac{w_{\text {pi\&st }} \cdot g \cdot b}{a},
$$

where " $w_{\text {pi\&st }}$ " is equal to the weight of the handled material during the picking and storing activity; " $b$ " is the distance between the body axis and the load axis; " $g$ " is the gravitational acceleration; and " $a$ " is the length of the load on the spine. The force load of pushing can be calculated as follows:

$$
F_{\text {load }}^{\mathrm{pu}}=\frac{w_{\mathrm{pu}} \cdot g \cdot \mu \cdot d}{c},
$$

where " $w_{\mathrm{pu}}$ " is equal to the weight of the handled material during the pushing activity; " $g$ " is the gravitational acceleration; " $\mu$ " is the coefficient of rolling friction; " $d$ " is the distance between the shoulder and the waist; and " $c$ " is the height of the load on the spine. Additionally, the $F_{\max }$ parameter for the investigated activities can be calculated as follows:
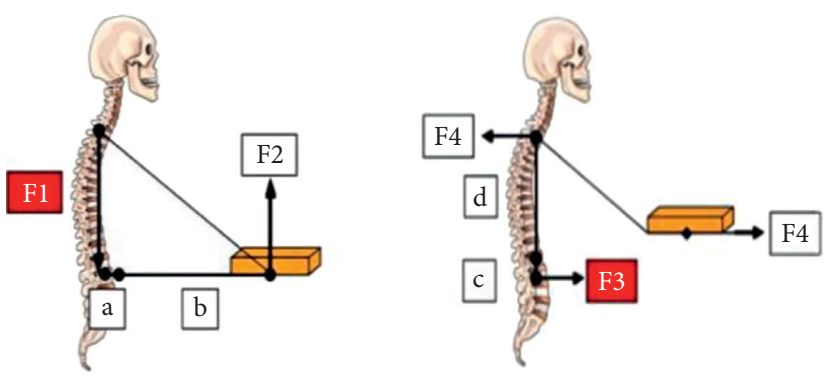

FIgURE 4: The representation of the load on the spine for picking, storing, and pushing.

$$
F_{\max }^{\mathrm{pi \& st}}=\frac{w_{\mathrm{pi} \& \mathrm{st}}^{\max } \cdot g \cdot b}{a},
$$

for picking and storing, and

$$
F_{\max }^{\mathrm{pu}}=\frac{w_{\mathrm{pu}}^{\max } \cdot g \cdot \mu \cdot d}{c},
$$

for pushing, where the maximum force load for picking and storing $\left(F_{\max }^{\text {pi\&st }}\right)$ is equal to $2452.5 \mathrm{~N}$, and it is calculated according to ISO-11228 on Ergonomics-Manual Handling, Part 1: Lifting and Carrying [67], where the limit for twohanded lifting is $25 \mathrm{~kg}$. The maximum force load for pushing $\left(F_{\mathrm{max}}^{\mathrm{pu}}\right)$ is calculated as $4326.2 \mathrm{~N}$ as suggested by Resnik and Chaffin [68] for the load limit of $225 \mathrm{~kg}$ for four-wheeled carts. According to the relaxation formulation, rest time is necessary if the fMVC is higher than 0.15 . With this constraint, "RT" can be expressed by the linear function of the tangent plane approximation (see Appendix B):

$$
\mathrm{RT}=A_{\mathrm{re}} \cdot t+\left(B_{\mathrm{re}} \cdot \mathrm{fMVC}\right)-C_{\mathrm{re}}
$$

where $A_{\text {re }}$ is the coefficient of contraction time, $B_{\text {re }}$ is the coefficient of relative force, and $C_{\mathrm{re}}$ is the constant of rest time. The linear function of rest time and endurance time can be defined as follows:

$$
\mathrm{RT}=3.6419 \cdot t+(32.2251 \cdot \mathrm{fMVC})-5.3225 .
$$

4.3. The Mathematical Model. In our discrete-event-based model, we can simulate for $t=1$ to $T$ interval according to the actual values of the aforementioned parameters, which describe the effects of investigation in the production line supply. We introduce the following binary decision variables. $x_{\text {mat }, t}$ indicates whether the material "mat" is placed in the cart at the " $t$-th" time slot $\left(x_{\text {mat }, t}=1\right)$ or not $\left(x_{\text {mat }, t}=0\right)$. Likewise, $x_{\mathrm{em}, t}$ indicates whether the empty unit "em" is placed in the cart at the " $t$-th" time slot $\left(x_{\mathrm{em}, t}=1\right)$ or not $\left(x_{\mathrm{em}, t}=0\right)$. Based on the problem description in the third section and the relevant cost components, the calculation of the different time components in our MMSO model is as follows.

Operational time need (OT):

$$
\mathrm{OT}_{t}=\mathrm{OT}_{\mathrm{mat}, t}+\mathrm{OT}_{\mathrm{em}, t} \text {. }
$$


The operational time need for the materials to be han- where dled will be determined by the AIM method:

$$
\mathrm{OT}_{\text {mat }, t}=\sum_{\text {mat }=1}^{M}\left(\mathrm{OT}_{\text {mat }, t}^{\mathrm{pi}, s}+\mathrm{OT}_{\text {mat }, t}^{\mathrm{st}, c}+\mathrm{OT}_{\text {mat }, t}^{\mathrm{pu}}+\mathrm{OT}_{\mathrm{mat}, t}^{\mathrm{pi}, c}+\mathrm{OT}_{\mathrm{mat}, t}^{\mathrm{st}, p}\right),
$$

$$
\begin{aligned}
\mathrm{OT}_{\text {mat }, t}^{\mathrm{pi}, s} & =f_{\mathrm{AIM}}\left(w_{\text {mat }}^{\mathrm{uni}}, h^{\mathrm{pi}, s}, d_{c, s}\right), \\
\mathrm{OT}_{\text {mat }, t}^{\mathrm{st}, c} & =f_{\mathrm{AIM}}\left(w_{\text {mat }}^{\mathrm{uni}}, h^{\mathrm{st}, c}, d_{c, s}\right), \\
\mathrm{OT}_{\text {mat }, t}^{\mathrm{pu}} & =f_{\mathrm{AIM}}\left(\sum_{\text {mat }=1}^{M} x_{\text {mat }, t} \cdot w_{\text {mat }}^{\mathrm{uni}}, w_{\mathrm{ca}}, d_{s, p}\right), \\
x_{\text {mat }, t} & = \begin{cases}1, & \text { if the material } \\
0, & \text { otherwise, }\end{cases} \\
\mathrm{OT}_{\text {mat }, t}^{\mathrm{pi}, c} & =f_{\mathrm{AIM}}\left(w_{\text {mat }}^{\text {uni }}, h^{\mathrm{pi}, c}, d_{c, p}\right), \\
\mathrm{OT}_{\text {mat }, t}^{\mathrm{st}, p} & =f_{\mathrm{AIM}}\left(w_{\text {mat }}^{\text {uni }}, h^{\mathrm{st}, p}, d_{c, s}\right),
\end{aligned}
$$

where

$$
\begin{aligned}
& w_{\text {mat }}^{\text {uni }}=f_{\text {wnit }}\left(q_{\text {mat }}, w_{\text {mat }}, w_{\text {em }}\right)=q_{\text {mat }} \cdot w_{\text {mat }}+w_{\text {em }} \text {, } \\
& q_{\text {mat }}=f_{\text {qmat }}\left(t_{\text {mat }}^{\mathrm{av}}, t_{\text {tact }}, r_{\text {mat }}\right)=\frac{t_{\text {mat }}^{\mathrm{av}}}{t_{\text {tact }} \cdot r_{\text {mat }}}, \quad \text { where } \operatorname{MIN}\left(t_{\text {mat }}^{\mathrm{av}}\right) \geq \operatorname{MAX}\left(\mathrm{OT}_{t}+\mathrm{RT}_{t}\right) \text {, }
\end{aligned}
$$

where $\mathrm{OT}_{t}$ is operational time need to be generated at a time slot " $t$." $\mathrm{OT}_{\text {mat, } t}$ is the operational time need for handling the material "mat" at a time slot " $t$." $\mathrm{OT}_{\mathrm{mat}, t}^{\mathrm{pi}, s}$ is the operational time need for picking the material "mat" from the supermarket at a time slot " $t$," and it is a function of the weight of the handled unit for material "mat" $\left(0<w_{\text {mat }}^{\text {uni }}<25 \mathrm{~kg}\right)$, the height of placement of the supermarket for picking $\left(0 \leq h^{\mathrm{pi}, s}<2 \mathrm{~m}\right)$, and the distance between the cart and the supermarket $\left(d_{c, s}>0\right)$. OT mat,$t^{\mathrm{st}, c}$ is the operational time need for storing the material "mat" to the cart at a time slot " $t$," and it is a function of the weight of the handled unit for material "mat" $\left(w_{\mathrm{mat}}^{\mathrm{uni}}\right)$, the height of placement of the cart for storing $\left(0 \leq h^{\mathrm{st}, c}<1,5 \mathrm{~m}\right)$, and distance between the cart and the supermarket $\left(d_{c, s}\right)$. $\mathrm{OT}_{\mathrm{mat}, t}^{\mathrm{pu}}$ is the operational time need for pushing the material "mat" to the production line at a time slot " $t$," and it is a function of the total weight of the materials "mat" placed in the cart at the time slot " $t$ " (calculated as $\left.\sum_{\mathrm{mat}=1}^{M} x_{\mathrm{mat}, t} \cdot w_{\mathrm{mat}}^{\mathrm{uni}}\right)$, the weight of the cart $\left(0<w_{\mathrm{ca}}<50 \mathrm{~kg}\right)$, and distance between the supermarket and the production line $\left(d_{s, p}>0\right)$. OT $\mathrm{OT}_{\mathrm{mat}, t}^{\mathrm{pi}, \mathrm{c}}$ is the operational time need for picking the material "mat" from the cart at a time slot " $t$," and it is a function of the weight of the handled unit for material "mat" ( $\left.w_{\text {mat }}^{\text {uni }}\right)$, the height of placement of the cart for picking $\left(0 \leq h^{\mathrm{pi}, c}<1,5 \mathrm{~m}\right)$, and distance between the cart and the production line $\left(d_{c, p}>0\right) . \mathrm{OT}_{\mathrm{mat}, t}^{\mathrm{st}, p}$ is the operational time need for storing the material "mat" to the production line at a time slot " $t$," and it is a function of the weight of the handled unit for material "mat" $\left(w_{\mathrm{mat}}^{\mathrm{uni}}\right)$, the height of placement of the production line for storing $\left(0 \leq h^{\text {st }, p}<2 \mathrm{~m}\right)$, and distance between the cart and the supermarket $\left(d_{c, s}\right)$.

$f_{\text {AIM }}$ means that the operational time needs are determined by the aforementioned AIM method, as a function of the weight, height, and distance parameters of the operation. $f_{\text {wunit }}$ means that the weight of the handled logistics unit is interpreted as a function of the lot size $\left(q_{\text {mat }}>0\right.$ and $\left.q_{\text {mat }} \in \mathbb{Z}^{+}\right)$, and the weight of the material $\left(0<w_{\text {mat }} \leq 1 \mathrm{~kg}\right)$, and the applied empty unit $\left(0<w_{\text {em }} \leq 1 \mathrm{~kg}\right)$. $f_{\text {gmat }}$ means that the lot size of the material is interpreted as a function of the material requirement per product $\left(r_{\text {mat }}>0\right.$ and $\left.r_{\text {mat }} \in \mathbb{Z}^{+}\right)$, the applied tact time of the production line $\left(t_{\text {tact }}>0\right)$, and the previous availability time of the material on the production line $\left(t_{\text {mat }}^{\text {av }}>0\right)$. In the model developed, we aim to use this availability time as a decision variable for all of the materials investigated and, in this way, to determine the lot sizes.

The operational time need for the empty units will be determined by the AIM method: 


$$
\mathrm{OT}_{\mathrm{em}, t}=\sum_{\mathrm{em}=1}^{E}\left(\mathrm{OT}_{\mathrm{em}, t}^{\mathrm{pi}, p}+\mathrm{OT}_{\mathrm{em}, t}^{\mathrm{st}, c}+\mathrm{OT}_{\mathrm{em}, t}^{\mathrm{pu}}+\mathrm{OT}_{\mathrm{em}, t}^{\mathrm{pi}, c}+\mathrm{OT}_{\mathrm{em}, t}^{\mathrm{st}, s}\right)
$$

where

$$
\begin{aligned}
\mathrm{OT}_{\mathrm{em}, t}^{\mathrm{pi}, p} & =f_{\mathrm{AIM}}\left(w_{\mathrm{em}}, h^{\mathrm{pi}, p}, d_{c, p}\right), \\
\mathrm{OT}_{\mathrm{em}, t}^{\mathrm{st}, c} & =f_{\mathrm{AIM}}\left(w_{\mathrm{em}}, h^{\mathrm{st}, c}, d_{c, p}\right), \\
\mathrm{OT}_{\mathrm{em}, t}^{\mathrm{pu}} & =f_{\mathrm{AIM}}\left(\sum_{\mathrm{em}=1}^{E} x_{\mathrm{em}, t} \cdot w_{\mathrm{em}}, w_{\mathrm{ca}}, d_{s, p}\right), \\
x_{\mathrm{em}, t} & = \begin{cases}1, & \text { if the empty “em" is placed in the cart at the “ } t \text { " - th time slot, } \\
0, & \text { otherwise, }\end{cases} \\
\mathrm{OT}_{\mathrm{em}, t}^{\mathrm{pi}, c} & =f_{\mathrm{AIM}}\left(w_{\mathrm{em}}, h^{\mathrm{pi}, c}, d_{c, s}\right), \\
\mathrm{OT}_{\mathrm{em}, t}^{\mathrm{st}, s} & =f_{\mathrm{AIM}}\left(w_{\mathrm{em}}, h^{\mathrm{st}, s}, d_{c, s}\right),
\end{aligned}
$$

where $\mathrm{OT}_{\mathrm{em}, t}$ is the total operational time need for handling the empty "em" at a time slot " $t$. " $\mathrm{OT}_{\mathrm{em}, t}^{\mathrm{pi}, p}$ is the operational time need for picking the empty "em" from the production line at a time slot " $t$," and it is a function of the weight of the empty "em" $\left(w_{\mathrm{em}}\right)$, the height of placement of the production line for picking $\left(h^{\mathrm{pi}, p}\right)$, and distance between the cart and the production line $\left(d_{c, p}\right) . \mathrm{OT}_{\mathrm{em}, t}^{\mathrm{st}, c}$ is the operational time need for storing the empty "em" to the cart at a time slot " $t$," and it is a function of the weight of the empty "em" $\left(w_{\text {em }}\right)$, the height of placement of the cart for storing $\left(h^{\text {st, } c}\right)$, and distance between the cart and the production line $\left(d_{c, p}\right)$. $\mathrm{OT}_{\mathrm{em}, t}^{\mathrm{pu}}$ is the operational time need for pushing the empty "em" to the supermarket at a time slot " $t$," and it is a function of the total weight of the empties "em" placed in the cart at the time slot " $t$ " (calculated as $\sum_{\mathrm{em}=1}^{E} x_{\mathrm{em}, t} \cdot w_{\mathrm{em}}$ ), the weight of the cart $\left(w_{\mathrm{ca}}\right)$, and distance between the supermarket and the production line $\left(d_{s, p}\right)$. $\mathrm{OT}_{\mathrm{em}, t}^{\mathrm{pi}, c}$ is the operational time need for picking the empty "em" from the cart at a time slot " $t$," and it is a function of the weight of the empty "em" $\left(w_{\mathrm{em}}\right)$, the height of placement of the cart for picking $\left(h^{\mathrm{pi}, c}\right)$, and distance between the cart and the supermarket $\left(d_{c, s}\right)$. $\mathrm{OT}_{\mathrm{em}, t}^{\mathrm{st}, s}$ is the operational time need for storing the empty "em" to the supermarket at a time slot " $t$," and it is a function of the weight of the empty "em" $\left(w_{\mathrm{em}}\right)$, the height of placement of the supermarket for storing $\left(h^{\text {st,s }}\right)$, and distance between the cart and the supermarket $\left(d_{c, s}\right)$.

Rest time need (RT):

$$
\mathrm{RT}_{t}=\mathrm{RT}_{\text {mat }, t}+\mathrm{RT}_{\mathrm{em}, t} .
$$

The rest time need for the materials to be handled:

$$
\mathrm{RT}_{\text {mat }, t}=\sum_{\text {mat }=1}^{M}\left(\mathrm{RT}_{\text {mat }, t}^{\mathrm{pi}, s}+\mathrm{RT}_{\text {mat }, t}^{\mathrm{st}, c}+\mathrm{RT}_{\text {mat }, t}^{\mathrm{pu}}+\mathrm{RT}_{\text {mat }, t}^{\mathrm{pi}, c}+\mathrm{RT}_{\text {mat }, t}^{\mathrm{st}, p}\right),
$$

where

$$
\begin{aligned}
& \mathrm{RT}_{\mathrm{mat}, t}^{\mathrm{pi}, s}=A_{\mathrm{re}} \cdot \mathrm{OT}_{\mathrm{mat}, t}^{\mathrm{pi}, s}+\left(B_{\mathrm{re}} \cdot \mathrm{fMVC}_{\mathrm{mat}}^{\mathrm{uni}}\right)-C_{\mathrm{re}} \\
& \mathrm{RT}_{\mathrm{mat}, t}^{\mathrm{st}, c}=A_{\mathrm{re}} \cdot \mathrm{OT}_{\mathrm{mat}, t}^{\mathrm{st}, c}+\left(B_{\mathrm{re}} \cdot \mathrm{fMVC}_{\mathrm{mat}}^{\mathrm{uni}}\right)-C_{\mathrm{re}} \\
& \mathrm{RT}_{\mathrm{mat}, t}^{\mathrm{pu}}=A_{\mathrm{re}} \cdot \mathrm{OT}_{\mathrm{mat}, t}^{\mathrm{pu}}+\left(B_{\mathrm{re}} \cdot \mathrm{fMVC}_{\mathrm{mat}, t}\right)-C_{\mathrm{re}} \\
& \mathrm{RT}_{\mathrm{mat}, t}^{\mathrm{pi}, c}=A_{\mathrm{re}} \cdot \mathrm{OT}_{\mathrm{mat}, t}^{\mathrm{pi}, c}+\left(B_{\mathrm{re}} \cdot \mathrm{fMVC}_{\mathrm{mat}}^{\mathrm{uni}}\right)-C_{\mathrm{re}} \\
& \mathrm{RT}_{\mathrm{mat}, t}^{\mathrm{st}, p}=A_{\mathrm{re}} \cdot \mathrm{OT}_{\mathrm{mat}, t}^{\mathrm{st}, p}+\left(B_{\mathrm{re}} \cdot \mathrm{fMVC}_{\mathrm{mat}}^{\mathrm{uni}}\right)-C_{\mathrm{re}}
\end{aligned}
$$

where

$$
\begin{aligned}
\mathrm{fMVC}_{\text {mat }}^{\mathrm{uni}} & =\frac{\left(\left(w_{\mathrm{mat}}^{\mathrm{uni}} \cdot g \cdot b\right) / a\right)}{F_{\text {max }}^{\mathrm{pi} i s t}}, \\
\mathrm{fMVC}_{\text {mat }, t} & =\frac{\left(\left(\left(w_{c a}+\sum_{\mathrm{mat}=1}^{M} x_{\mathrm{mat}, t} \cdot w_{\mathrm{mat}}^{\mathrm{uni}}\right) \cdot g \cdot \mu \cdot d\right) / c\right)}{F_{\text {max }}^{\mathrm{pu}}}, \\
x_{\text {mat }, t} & = \begin{cases}1, & \text { if the material "mat" is placed in the cart at the " } t \text { " - th time slot, } \\
0, & \text { otherwise, }\end{cases}
\end{aligned}
$$


where $\mathrm{RT}_{t}$ is the rest time need to be generated at a time slot " $t$." $\mathrm{RT}_{\text {mat }, t}$ is the rest time need for handling the material "mat" at a time slot " $t$." $\mathrm{RT}_{\mathrm{mat}, t}^{\mathrm{pi}, \mathrm{s}}$ is the rest time need for picking the material "mat" from the supermarket at a time slot " $t$," and it is a function of the operational time need for picking the material "mat" from the supermarket at a time slot " $t$ " $\left(\mathrm{OT}_{\mathrm{mat}, t}^{\mathrm{pi} s}\right)$, the relative force of the unit weight of the material "mat" for picking and storing motions ( $\mathrm{fMVC}_{\mathrm{mat}}^{\mathrm{uni}}$ ), the coefficient of contraction time $\left(A_{\mathrm{re}}\right)$, the coefficient of relative force $\left(B_{\mathrm{re}}\right)$, and the constant of rest time $\left(C_{\mathrm{re}}\right)$. $\mathrm{RT}_{\text {mat }, t}^{\text {st, }}$ is the rest time need for storing the material "mat" to the cart at a time slot " $t$," and it is a function of the operational time need for storing the material "mat" to the cart at a time slot " $t$ " $\left(\mathrm{OT}_{\text {mat }, t}^{\mathrm{st}, c}\right)$, the relative force of the unit weight of the material "mat" for picking and storing motions ( $\mathrm{fMVC}$ mat $)$, the coefficient of contraction time $\left(A_{\mathrm{re}}\right)$, the coefficient of relative force $\left(B_{\text {re }}\right)$, and the constant of rest time $\left(C_{\mathrm{re}}\right) \cdot \mathrm{RT}_{\mathrm{mat}, t}^{\mathrm{pu}}$ is the rest time need for pushing the material "mat" to the production line at a time slot " $t$," and it is a function of the operational time need for pushing the material "mat" to the production line at a time slot " $t$ " $\left(\mathrm{OT}_{\mathrm{mat}, t}^{\mathrm{pu}}\right)$, the relative force of the unit weight of the materials "mat" for pushing motion $\left(\mathrm{fMVC}_{\mathrm{mat}, t}\right)$, the coefficient of contraction time $\left(A_{\mathrm{re}}\right)$, the coefficient of relative force $\left(B_{\mathrm{re}}\right)$, and the constant of rest time $\left(C_{\mathrm{re}}\right) . \mathrm{RT}_{\mathrm{mat}, t}^{\mathrm{pi}, \mathrm{c}}$ is the rest time need for picking the material "mat" from the cart at a time slot " $t$," and it is a function of the operational time need for picking the material "mat" from the cart at a time slot " $t$ " $\left(\mathrm{OT}_{\mathrm{mat}, t}^{\mathrm{pi}, c}\right.$ ), the relative force of the unit weight of the material "mat" for picking and storing motions ( $\mathrm{MVC}_{\mathrm{mat}}^{\mathrm{uni}}$ ), the coefficient of contraction time $\left(A_{\mathrm{re}}\right)$, the coefficient of relative force $\left(B_{\mathrm{re}}\right)$, and the constant of rest time $\left(C_{\mathrm{re}}\right) \cdot \mathrm{RT}_{\text {mat }, t}^{\mathrm{st}, p}$ is the rest time need for storing the material "mat" to the production line at a time slot " $t$," and it is a function of the operational time need for storing the material "mat" to the production line at a time slot " $t$ " ( $\left.\mathrm{OT}_{\text {mat }, t}^{\mathrm{st}, p}\right)$, the relative force of unit weight of the material "mat" for picking and storing motions ( $\mathrm{fMVC}_{\mathrm{mat}}^{\mathrm{uni}}$ ), the coefficient of contraction time $\left(A_{\mathrm{re}}\right)$, the coefficient of relative force $\left(B_{\mathrm{re}}\right)$, and the constant of rest time $\left(C_{\mathrm{re}}\right)$.

The relative force for picking and storing and pushing activities can be calculated using the previously described methodology in Section 4.2, where in this case, $w_{\text {pi\&st }}=w_{\mathrm{mat}}^{\mathrm{uni}}$ and $w_{\mathrm{pu}}=w_{\mathrm{ca}}+\sum_{\mathrm{mat}}^{M} x_{\mathrm{mat}, t} \cdot w_{\mathrm{mat}}^{\mathrm{uni}}$. Based on this, it can be seen that the calculated values also depend on the weight of the units handled ( $w_{\text {mat }}^{\text {uni }}$ ) and therefore the lot sizes calculated $\left(q_{\text {mat }}\right)$. To calculate the rest time needed, a linearized rest time formula (equation (7) was used.

The rest time need for the empty units to be handled:

$$
\mathrm{RT}_{\mathrm{em}, t}=\sum_{\mathrm{em}=1}^{E}\left(\mathrm{RT}_{\mathrm{em}, t}^{\mathrm{pi}, p}+\mathrm{RT}_{\mathrm{em}, t}^{\mathrm{st}, c}+\mathrm{RT}_{\mathrm{em}, t}^{\mathrm{pu}}+\mathrm{RT}_{\mathrm{em}, t}^{\mathrm{pi}, c}+\mathrm{RT}_{\mathrm{em}, t}^{\mathrm{st}, s}\right)
$$

where

$$
\begin{aligned}
& \mathrm{RT}_{\mathrm{em}, t}^{\mathrm{pi}, p}=A_{\mathrm{re}} \cdot \mathrm{OT}_{\mathrm{em}, t}^{\mathrm{pi}, p}+\left(B_{\mathrm{re}} \cdot \mathrm{fMVC}_{\mathrm{em}}\right)-C_{\mathrm{re}} \\
& \mathrm{RT}_{\mathrm{em}, t}^{\mathrm{st}, c}=A_{\mathrm{re}} \cdot \mathrm{OT}_{\mathrm{em}, t}^{\mathrm{st}, c}+\left(B_{\mathrm{re}} \cdot \mathrm{fMVC}_{\mathrm{em}}\right)-C_{\mathrm{re}} \\
& \mathrm{RT}_{\mathrm{em}, t}^{\mathrm{pu}}=A_{\mathrm{re}} \cdot \mathrm{OT}_{\mathrm{em}, t}^{\mathrm{pu}}+\left(B_{\mathrm{re}} \cdot \mathrm{fMVC}_{\mathrm{em}, t}\right)-C_{\mathrm{re}} \\
& \mathrm{RT}_{\mathrm{em}, t}^{\mathrm{pi}, c}=A_{\mathrm{re}} \cdot \mathrm{OT}_{\mathrm{em}, t}^{\mathrm{pi}, c}+\left(B_{\mathrm{re}} \cdot \mathrm{fMVC}_{\mathrm{em}}\right)-C_{\mathrm{re}} \\
& \mathrm{RT}_{\mathrm{em}, t}^{\mathrm{st}, s}=A_{\mathrm{re}} \cdot \mathrm{OT}_{\mathrm{em}, t}^{\mathrm{st}, s}+\left(B_{\mathrm{re}} \cdot \mathrm{fMVC}_{\mathrm{em}}\right)-C_{\mathrm{re}}
\end{aligned}
$$

where

$$
\begin{aligned}
\mathrm{fMVC}_{\mathrm{em}} & =\frac{\left(\left(w_{\mathrm{em}} \cdot g \cdot b\right) / a\right)}{F_{\text {max }}^{\mathrm{p} \& \mathrm{st}}}, \\
\mathrm{fMVC}_{\mathrm{em}, t} & =\frac{\left(\left(\left(w_{\mathrm{ca}}+\sum_{\mathrm{em}=1}^{E} x_{\mathrm{em}, t} \cdot w_{\mathrm{em}}\right) \cdot g \cdot \mu \cdot d\right) / c\right)}{F_{\text {max }}^{\mathrm{pu}}}, \\
x_{\mathrm{em}, t} & = \begin{cases}1, & \text { if the empty "em" is placed in the cart at the " } t \text { " }- \text { th time slot, } \\
0, & \text { otherwise, }\end{cases}
\end{aligned}
$$

where $\mathrm{RT}_{\mathrm{em}, t}$ is the rest time need for handling the empty "em" at a time slot " $t$." $\mathrm{RT}_{\mathrm{em}, t}^{\mathrm{pi}, p}$ is the rest time need for picking the empty unit "em" from the production line at a time slot " $t$," and it is a function of the operational time need for picking the empty "em" from the production line at a time slot " $t$ " $\left(\mathrm{OT}_{\mathrm{em}, t}^{\mathrm{pi}, p}\right)$, the relative force for the empty "em" for picking and storing motions ( $\mathrm{FVC}_{\mathrm{em}}$ ), the coefficient of contraction time $\left(A_{\mathrm{re}}\right)$, the coefficient of relative force $\left(B_{\mathrm{re}}\right)$, and the constant of rest time $\left(C_{\mathrm{re}}\right)$. $\mathrm{RT}_{\mathrm{em}, t}^{\mathrm{st}, \mathrm{c}}$ is the rest time need for storing the empty unit "em" to the cart at a time slot " $t$," and it is a function of the operational time need for storing the empty "em" to the cart at a time slot " $t$ " $\left(\mathrm{OT}_{\mathrm{em}, t}^{\mathrm{st}, c}\right)$, the relative force for the empty "em" for picking and storing motions $\left(\mathrm{fMVC}_{\mathrm{em}}\right)$, the coefficient of contraction time $\left(A_{\text {re }}\right)$, the coefficient of relative force $\left(B_{\mathrm{re}}\right)$, and the constant of rest time $\left(C_{\mathrm{re}}\right)$. $\mathrm{RT}_{\mathrm{em}, t}^{\mathrm{pu}}$ is the rest time need for pushing the empty unit "em" to the supermarket at a time slot " $t$," and it is a function of the operational time need for pushing the empty "em" to the supermarket at a time slot " $t$ " $\left(\mathrm{OT}_{\mathrm{em}, t}^{\mathrm{pu}}\right)$, the relative force for empties "em" for pushing motion $\left(\mathrm{fMVC}_{\mathrm{em}, t}\right)$, the coefficient of contraction time $\left(A_{\mathrm{re}}\right)$, the 
coefficient of relative force $\left(B_{\text {re }}\right)$, and the constant of rest time $\left(C_{\mathrm{re}}\right) \cdot \mathrm{RT}_{\mathrm{em}, t}^{\mathrm{pi}, \mathrm{i}}$ is the rest time need for picking the empty unit "em" from the cart at a time slot " $t$," and it is a function of the operational time need for picking the empty "em" from the cart at a time slot " $t$ " $\left(\mathrm{OT}_{\mathrm{em}, t}^{\mathrm{p}, \mathrm{c}}\right)$, the relative force for the empty "em" for picking and storing motions $\left(\mathrm{fMVC}_{\mathrm{em}}\right)$, the coefficient of contraction time $\left(A_{\mathrm{re}}\right)$, the coefficient of relative force $\left(B_{\mathrm{re}}\right)$, and the constant of rest time $\left(C_{\mathrm{re}}\right)$. $\mathrm{RT}_{\mathrm{em}, t}^{\mathrm{st}, \mathrm{s}}$ is the rest time need for storing the empty unit "em" to the supermarket at a time slot " $t$," and it is a function of the operational time need for storing the empty "em" to the supermarket at a time slot " $t$ " $\left(\mathrm{OT}_{\mathrm{em}, t}^{\mathrm{st}, s}\right)$, the relative force for the empty "em" for picking and storing motions $\left(\mathrm{fMVC}_{\mathrm{em}}\right)$, the coefficient of contraction time $\left(A_{\mathrm{re}}\right)$, the coefficient of relative force $\left(B_{\mathrm{re}}\right)$, and the constant of rest time $\left(C_{\mathrm{re}}\right)$.

The calculation of relative force and the rest time need can be realized in a similar way as in the previously mentioned case, but in this case, $w_{\mathrm{pi} s \mathrm{st}}=w_{\mathrm{em}}$ and $w_{\mathrm{pu}}=w_{\mathrm{ca}}+$ $\sum_{\mathrm{em}=1}^{E} x_{\mathrm{em}, t} \cdot w_{\mathrm{em}}$ equations must be considered.

The cost of operation, the cost of rest time, and the cost of inventory holding can be described as follows:

$$
\begin{aligned}
& C^{\mathrm{OP}}=\sum_{t=1}^{T} C_{t}^{\mathrm{OP}}=\sum_{t=1}^{T} c_{w} \cdot \mathrm{OT}_{t}, \\
& C^{\mathrm{RT}}=\sum_{t=1}^{T} C_{t}^{\mathrm{RT}}=\sum_{t=1}^{T} c_{w} \cdot \mathrm{RT}_{t}, \\
& C^{\mathrm{HO}}=\sum_{t=1}^{T} C_{t}^{\mathrm{HO}}=\sum_{t=1}^{T} \sum_{\text {mat }=1}^{M} c_{h, \text { mat }} \cdot Q_{\text {mat }, t} \cdot
\end{aligned}
$$

The total cost can be calculated as follows:

$$
\mathrm{C}=\mathrm{C}^{\mathrm{OP}}+\mathrm{C}^{\mathrm{HO}}+C^{\mathrm{RT}} \text {. }
$$

The objective function can be written as follows:

$$
\min \left\{\sum_{t=1}^{T}\left(c_{w} \cdot\left(\mathrm{OT}_{t}+\mathrm{RT}_{t}\right)+\sum_{\mathrm{mat}=1}^{M} c_{h, \mathrm{mat}} \cdot \mathrm{Q}_{\mathrm{mat}, t}\right)\right\} .
$$

\section{Results}

5.1. Application of the New Model. We applied a numerical example to investigate the cost effects of rest time, where the total request of the production during the examined time period $(480 \mathrm{~min})$ related to the first material $\left(R_{\text {mat } 1}\right)$ is equal to 1440 pcs, that related to the second material $\left(R_{\text {mat } 2}\right)$ is equal to 960 pcs, that related to the third material $\left(R_{\text {mat3 } 3}\right)$ is equal to 480 pcs, the maximum force load of the human spine $\left(F_{\max }\right)$ for picking and storing is equal to $2452.5 \mathrm{~N}$, and it has been calculated according to IS0-11228 on Ergonomics-Manual Handling, Part 1: Lifting and Carrying [67], where the limit for two-handed lifting is $25 \mathrm{~kg}$. $F_{\max }$ for pushing is $4326.2 \mathrm{~N}$ as suggested by Resnik and Chaffin [68] for the load limit of $225 \mathrm{~kg}$ for four-wheeled carts. The cart weight $\left(w_{\mathrm{ca}}\right)$ is $15 \mathrm{~kg}$, the time for picking from the supermarket to the warehouse area is $0.11 \mathrm{~min}$ for three materials, the time for storing to the cart is $0.05 \mathrm{~min}$ for three materials, the time for pushing from the supermarket to the production area is $1.4 \mathrm{~min}$, the time for picking the materials from the cart is $0.07 \mathrm{~min}$, the time for storing the materials to the storage for production line supply is $0.05 \mathrm{~min}$, the time for picking the empties from the storage near the production line is $0.07 \mathrm{~min}$, the time for storing the empties to the cart is $0.05 \mathrm{~min}$, the time for pushing the empties from the production area to the supermarket at the warehouse is $0.7 \mathrm{~min}$, the time for picking the empties from the cart is $0.07 \mathrm{~min}$, and the time for storing the empties to the supermarket is $0.09 \mathrm{~min}$. Furthermore, the examined time period ( $T$ ) is $480 \mathrm{~min}$, the material need for the first material in the production line $\left(r_{\text {mat1 }}\right)$ is 3 pcs/product, the material need for the second material in the production line $\left(r_{\text {mat } 2}\right)$ is 2 pcs/ product, the material need for the third material in the production line $\left(r_{\text {mat3 } 3}\right)$ is 1 pcs/product, the tact time $\left(t_{\text {tact }}\right)$ for the production is $1 \mathrm{~min}$, the unit worker wage $\left(c_{w}\right)$ is $18 \mathrm{\$} / \mathrm{h}$, the cost of inventory holding for the first material $\left(c_{h, \text { mat } 1}\right)$ is $0.02 \$ / \mathrm{pcs} / \mathrm{h}$, the cost of inventory holding for the second material $\left(c_{h, \text { mat } 2}\right)$ is $0.04 \$ / \mathrm{pcs} / \mathrm{h}$, the cost of inventory holding for the third material $\left(c_{h \text {,mat } 3}\right)$ is $0.06 \$ / \mathrm{pcs} / \mathrm{h}$, the weight of the first material $\left(w_{\text {mat } 1}\right)$ is $0.1 \mathrm{~kg}$, the weight of the second material $\left(w_{\text {mat } 2}\right)$ is $0.2 \mathrm{~kg}$, the weight of the third material $\left(w_{\text {mat } 3}\right)$ is $0.3 \mathrm{~kg}$, the weight of the empties $\left(w_{\mathrm{em}}\right)$ is $1 \mathrm{~kg}$, " $\mu$ " is 0.28 , and " $g$ " is $9.81 \mathrm{~m} / \mathrm{s}^{2}$. The height of placement of the production line for storing $\left(h^{\mathrm{st}, p}\right)$ is $1.2 \mathrm{~m}$, the height of placement of the cart for picking $\left(h^{\mathrm{pi}, c}\right)$ is $0.8 \mathrm{~m}$, the height of placement of the supermarket for picking $\left(h^{\mathrm{pi}, s}\right)$ is $1.8 \mathrm{~m}$, the height of placement of the cart for storing $\left(h^{\mathrm{st}, c}\right)$ is $0.8 \mathrm{~m}$, the height of placement of the production line for picking $\left(h^{\mathrm{pi}, p}\right)$ is $1.2 \mathrm{~m}$, the height of placement of the supermarket for storing $\left(h^{\text {st,s }}\right)$ is $1.8 \mathrm{~m}$, the distance between the cart and the production line $\left(d_{c, p}\right)$ is $0.5 \mathrm{~m}$, the distance between the supermarket and the production line in the production area $\left(d_{s, p}\right)$ is $100 \mathrm{~m}$, and the distance between the cart and the supermarket $\left(d_{c, s}\right)$ is $0.5 \mathrm{~m}$. Anthropometrical parameters have been calculated as follows: " $a$ " and " $c$ " are equal to $0.05 \mathrm{~m}$ for picking, storing, and pushing, " $b$ " is equal to $0.5 \mathrm{~m}$ for picking and storing, and " $d$ " is equal to $0.35 \mathrm{~m}$ for pushing according to the work-related musculoskeletal disorders mentioned in the journal published by the Ministry of Labour and Social Security of Turkey [69].

We have used the following formal algorithm to calculate the necessary parameters:

$$
\begin{aligned}
& \text { For } t=1 \text { to } T \\
& \text { If } x_{\text {mat }, t}=1 \text { then } \\
& \text { For } \text { mat }=1 \text { to } M \\
& \text { Calculation of } \mathrm{OT}_{\text {mat, } t} \\
& \text { If } \mathrm{fMVC}_{\text {mat }}^{\mathrm{uni}} \geq 0,15 \text { then calculation of } \mathrm{RT}_{\text {mat, }, t}^{\mathrm{pi}, s}, \mathrm{RT}_{\text {mat }, t}^{\mathrm{st}, c} \text {, } \\
& \mathrm{RT}_{\text {mat }, t}^{\mathrm{pi}, c}, \mathrm{RT}_{\text {mat }, t}^{\mathrm{st}, p} \\
& \text { Elseif } \mathrm{fMVC}_{\text {mat }}^{\text {uni }}<0,15 \text { then } \mathrm{RT}_{\text {mat }, t}^{\mathrm{pi}, s}=\mathrm{RT}_{\text {mat, }, t}^{\mathrm{st}, c}=\mathrm{RT}_{\text {mat }, t}^{\mathrm{pi}, c} \\
& =\mathrm{RT}_{\text {mat }, t}^{\mathrm{st}, p}=0 \\
& \text { If } \mathrm{fMVC}_{\text {mat }, t} \geq 0,15 \text { then calculation of } \mathrm{RT}_{\text {mat }, t}^{\mathrm{pu}} \\
& \text { Elseif } \mathrm{fMVC}_{\text {mat }, t}<0,15 \text { then } \mathrm{RT}_{\mathrm{mat}, t}^{\mathrm{pu}}=0 \\
& \text { Calculation of } \mathrm{RT}_{\text {mat }, t} \\
& \text { If } x_{\mathrm{em}, t}=1 \text { then }
\end{aligned}
$$


For $\mathrm{em}=1$ to $E$

Calculation of $\mathrm{OT}_{\mathrm{em}, t}$

If $\mathrm{fMVC}_{\mathrm{em}} \geq 0,15$ then calculation of $\mathrm{RT}_{\mathrm{em}, t}^{\mathrm{pi}, p}$, $\mathrm{RT}_{\mathrm{em}, t}^{\mathrm{st}, c}, \mathrm{RT}_{\mathrm{em}, t}^{\mathrm{p}, c}, \mathrm{RT}_{\mathrm{em}, t}^{\mathrm{st}, s}$

Elseif $\quad \mathrm{fMVC}_{\mathrm{em}} \geq 0,15 \quad$ then $\quad \mathrm{RT}_{\mathrm{em}, t}^{\mathrm{pi}, p}=\mathrm{RT}_{\mathrm{em}, t}^{\mathrm{st}, c}=$ $\mathrm{RT}_{\mathrm{em}, t}^{\mathrm{pi}, c}=\mathrm{RT}_{\mathrm{em}, t}^{\mathrm{st}, s}=0$

If $\mathrm{fMVC}_{\mathrm{em}, t} \geq 0,15$ then calculation of $\mathrm{RT}_{\mathrm{em}, t}^{\mathrm{pu}}$

Elseif $\mathrm{fMVC}_{\mathrm{em}, t} \geq 0,15$ then $\mathrm{RT}_{\mathrm{em}, t}^{\mathrm{pu}}=0$

Calculation of $\mathrm{RT}_{\mathrm{em}, t}$

Calculation of $\mathrm{OT}_{t}$ and $\mathrm{RT}_{t}$

If $\operatorname{MIN}\left(t_{\text {mat }}^{\mathrm{av}}\right) \geq \operatorname{MAX}\left(\mathrm{OT}_{t}+\mathrm{RT}_{t}\right)$ then calculation of $C_{t}^{\mathrm{OP}}, C_{t}^{\mathrm{RT}}$, and $C_{t}^{\mathrm{HO}}$

Elseif $\operatorname{MIN}\left(t_{\text {mat }}^{\mathrm{av}}\right)<\operatorname{MAX}\left(\mathrm{OT}_{t}+\mathrm{RT}_{t}\right)$ then the situation is not valid, and no solution exists

5.1.1. Calculation of $C$ for the Examination Period $T$. The applied formal algorithm above can be described with $T(n)=4 n^{2}+4 n^{2}+n+n+1$ function. Therefore, the time complexity of the algorithm based on the Big $\mathrm{O}$ principle is $O\left(n^{2}\right)$

We applied our simulation model (see Figure 5) with the aforementioned algorithm to calculate the values of the parameters investigated and to find the ergonomically optimal lot sizes by using the solver application of Microsoft Excel for three materials where the total cost is minimum, $\operatorname{MIN}\left(t_{\text {mat }}^{\mathrm{av}}\right) \geq \operatorname{MAX}\left(\mathrm{OT}_{t}+\mathrm{RT}_{t}\right)$ andfMVC $\geq 0,15$. The minimum total cost equals to $C=130,36$ and rest time cost equals to $C^{\mathrm{RT}}=0$ where the ergonomically optimal lot size for the material one equals to $\left(q_{\text {mat } 1}\right) 27$ pcs, the material two equals to $\left(q_{\text {mat2 }}\right) 14$ pcs, and the material three equals to $\left(q_{\text {mat } 3}\right) 9$ pcs. The material availability of material one $\left(t_{\text {mat } 1}^{\mathrm{av}}\right)$ is equal to $9 \mathrm{~min}$, the material availability of material two $\left(t_{\text {mat2 } 2}^{\text {av }}\right)$ is equal to $7 \mathrm{~min}$, the material availability of material three $\left(t_{\mathrm{mat} 3}^{\mathrm{av}}\right)$ is equal to $9 \mathrm{~min}, \quad \operatorname{MIN}\left(t_{\mathrm{mat}}^{\mathrm{av}}\right) \geq \operatorname{MAX}\left(\mathrm{OT}_{t}+\mathrm{RT}_{t}\right)$ as $\operatorname{MIN}\left(t_{\text {mat }}^{\mathrm{av}}\right)=7 \mathrm{~min}$, and $\operatorname{MAX}\left(\mathrm{OT}_{t}+\mathrm{RT}_{t}\right)=4.39 \mathrm{~min}$ where $\mathrm{RT}_{t}=0 . \mathrm{RT}_{t}=0$ means that a logistics operator can work continuously without any need for rest time with these ergonomically optimal lot sizes. We have calculated the total cost of the maximum lifting and carrying limit $(25 \mathrm{~kg})$ according to ISO-11228 on Ergonomics-Manual Handling, Part 1: Lifting and Carrying [67], for two-handed lifting where each lot size is equal to $25 \mathrm{~kg}$ for the production supply process, and the lot size of material one $\left(q_{\text {mat1 }}\right)$ is equal to 240 pcs, the lot size of material two $\left(q_{\text {mat } 2}\right)$ is equal to 120 pcs, and the lot size of material three $\left(q_{\text {mat } 3}\right)$ is equal to 80 pcs. The total cost is equal to $C=149,93$ and $C^{\mathrm{RT}}=78,95 . C^{\mathrm{RT}}=$ 78,95 is the cost of the need for rest period of logistics operators to prevent any ergonomic risks. In our model, the saving achieved by using the ergonomic rest time and maximum endurance time in comparison to the total cost of the production supply process without ergonomics is equal to $13.05 \%$.

5.2. Parameteric Analysis. In this section, we have applied the mathematical model developed to different scenarios based on different parameter values derived from various industrial practices, and we have analyzed their impact on our new model. In addition, we have changed the weight of the three items from 0.01 to $3 \mathrm{~kg}$ in order to observe the effect of different materials. We have calculated the savings obtained by using our new model with different $w_{\text {mat }}^{\text {uni }}$ and different material needs in the production line for three different products. The savings have been calculated in comparison with the total cost of maximum lifting and carrying limit $(25 \mathrm{~kg}$ ) according to ISO-11228 on Ergonomics-Manual Handling, Part 1: Lifting and Carrying, for two-handed lifting where each lot size is equal to $25 \mathrm{~kg}$ and the optimal total cost of our model. Furthermore, we have calculated the savings where

$$
\begin{aligned}
& r_{\text {mat } 1}=3 \mathrm{pcs} ; \\
& r_{\text {mat } 2}=2 \mathrm{pcs} ; \\
& r_{\text {mat } 3}=1 \mathrm{pcs} ; \\
& r_{\text {mat } 1}=5 \mathrm{pcs} ; \\
& r_{\text {mat } 2}=3 \mathrm{pcs} ; \\
& r_{\text {mat } 3}=1 \mathrm{pcs} ; \\
& r_{\text {mat1 }}=r_{\text {mat2 }}=r_{\text {mat } 3}=1 \text { pcs }
\end{aligned}
$$

Figure 6 illustrates that savings increases or decreases by increase of the unit weight of items.. As we have calculated the savings regarding the maximum lifting and carrying limit determined by the ISO-11228 [67], the rest allowance stays constant as it increases each unit weight of materials "mat" but decreases the number of materials handled by causing an increase in the rest time cost and the operational cost.

We also conducted regression analysis for a better understanding of the relationship between variables. The regression analysis showed the relationship between the weight of handled materials and savings.

$r_{\text {mat } 1}=3$ pcs $; r_{\text {mat } 2}=2$ pcs $; r_{\text {mat } 3}=1$ pcs are statistically significant based on $p$ value $(0.007) ; r_{\text {mat } 1}=5$ pcs; $r_{\text {mat } 2}=$ 3 pcs; $r_{\text {mat } 3}=1$ pcs are statistically significant based on $p$ value $(0.025)$; and $r_{\text {mat } 1}=r_{\text {mat } 2}=r_{\text {mat3 }}=1$ pcs is statistically significant based on $p$ value $(0.001)$.

We have analyzed the material need of the first material in the production line $\left(r_{\text {mat1 }}\right)$ as 1 pcs/product, the material need of the second material in the production line $\left(r_{\text {mat } 2}\right)$ as $1 \mathrm{pcs} /$ product, and the material need of the third material in the production line $\left(r_{\text {mat3 } 3}\right)$ as 1 pcs/product, and, based on these different lot size values, we also analyzed how the total, operational, holding, and rest time costs change. Furthermore, we have applied the inventory holding cost of the first material $\left(c_{h \text { mat } 1}\right)$ as $0.04 \$ / \mathrm{pcs} / \mathrm{h}$, the inventory holding cost of the second material $\left(c_{h \text { mat } 2}\right)$ as $0.08 \$ / \mathrm{pcs} / \mathrm{h}$, the inventory holding cost of the third material $\left(c_{h, \text { mat } 3}\right)$ as $0.1 \$ / \mathrm{pcs} / \mathrm{h}$, the weight of the first material $\left(w_{\text {mat } 1}\right)$ as $0.2 \mathrm{~kg}$, the weight of the second material $\left(w_{\text {mat } 2}\right)$ as $0.3 \mathrm{~kg}$, the weight of the third material $\left(w_{\text {mat } 3}\right)$ as $0.4 \mathrm{~kg}$, the weight of the empties $\left(w_{\mathrm{em}}\right)$ as $1 \mathrm{~kg}$, " $\mu$ " as 0.28 , and " $g$ " as $9.81 \mathrm{~m} / \mathrm{s}^{2}$, and other parameters were constant. The analysis results are given in Figure 7, where the lot size increases, especially the rest time, the cost 

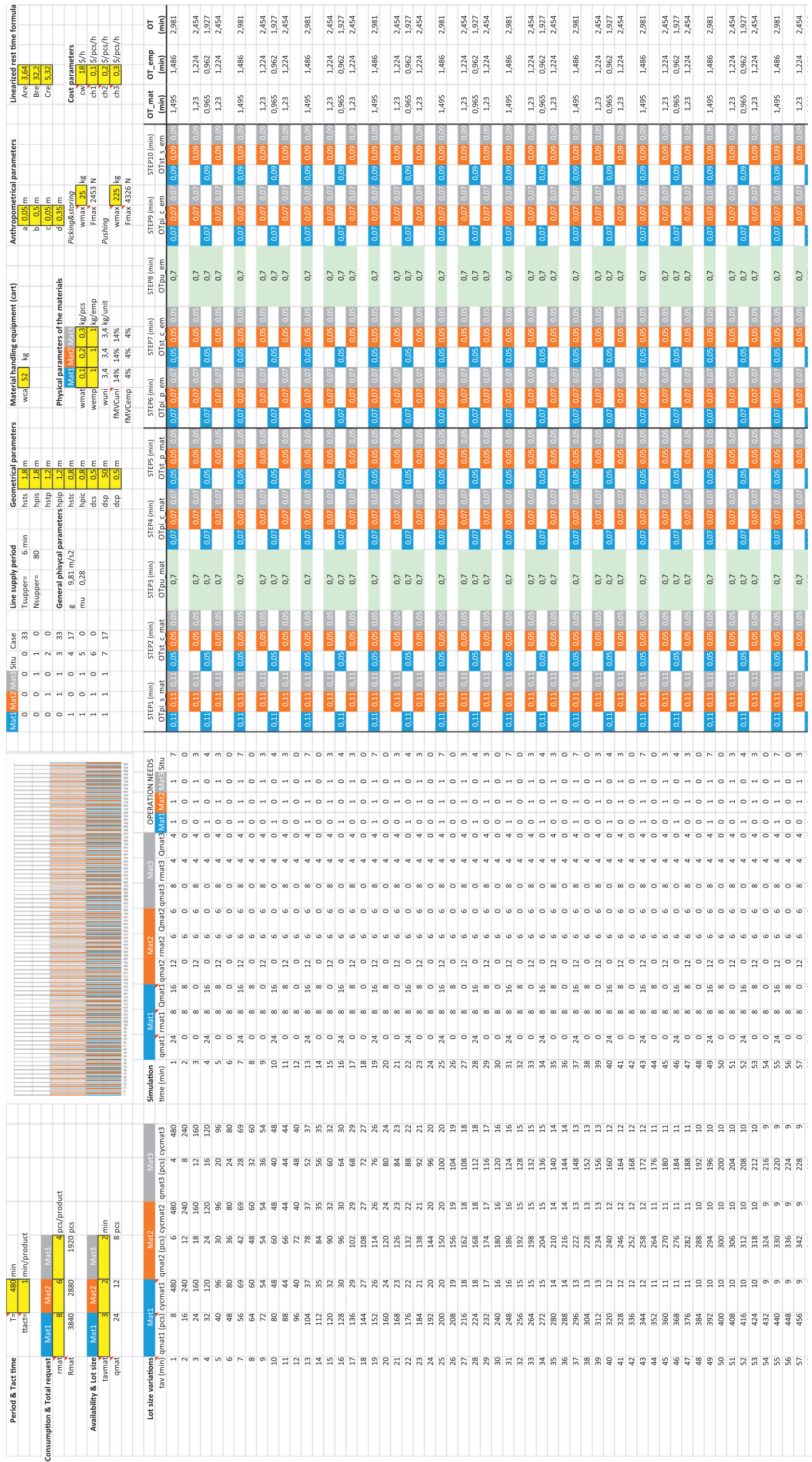

FIGURE 5: The result of a simulation experiment in case of the investigated numerical example in our specific simulator developed in MS Excel. 


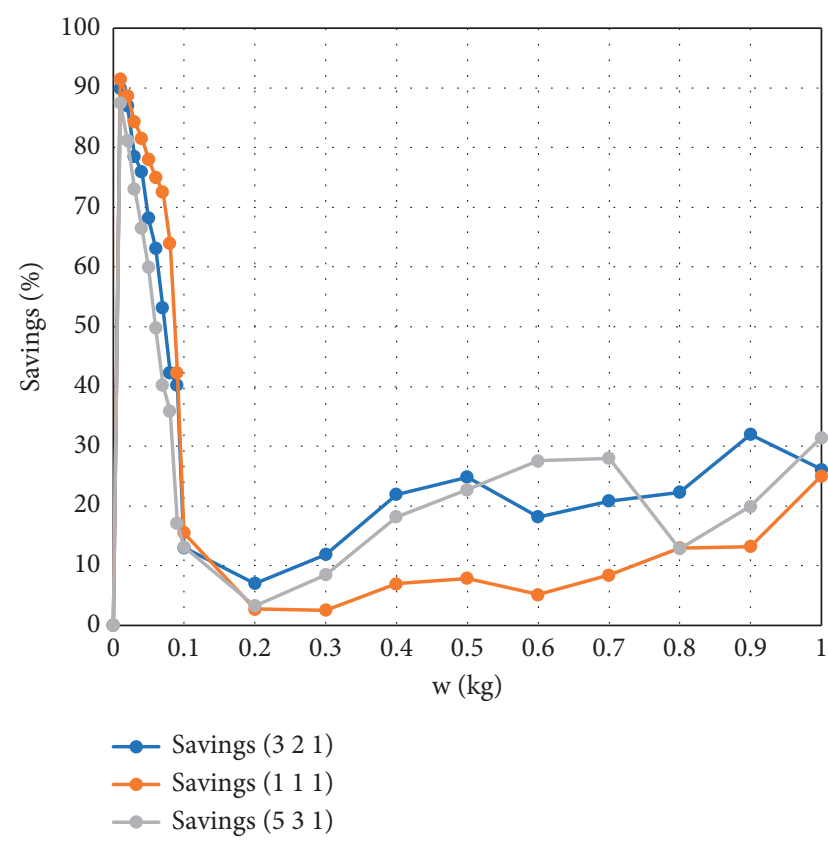

FIgURE 6: The savings for different weights of each material.

of rest allowance, and the holding cost. As can be seen, the optimal solution of the model suggests that the lot size needs to be decreased for a decrease in the total cost, the holding cost, and the rest time cost.

To analyze the effect of the height of placement of the materials, we have applied different values:

$$
\begin{aligned}
& h^{\mathrm{st}, p}(1.7,1.6,1.5,1.4,1.3,1.2,1.1,1,0.9,0.8,0.7,0.6 \\
& 0.5) . \\
& h^{\mathrm{pi}, \mathcal{c}}(1.4,1.3,1.2,1.1,1,0.9,0.8,0.7,0.6,0.5,0.4,0.3 \\
& 0.2) . \\
& h^{\mathrm{pi}, s}(2,1.9,1.8,1.7,1.6,1.5,1.4,1.3,1.2,1.1,1,0.9,0.8) \\
& h^{\mathrm{st}, c}(1.4,1.3,1.2,1.1,1,0.9,0.8,0.7,0.6,0.5,0.4,0.3 \\
& 0.2) . \\
& h^{\mathrm{pi}, p}(1.7,1.6,1.5,1.4,1.3,1.2,1.1,1,0.9,0.8,0.7,0.6 \\
& 0.5) . \\
& h^{\mathrm{st}, s}(2,1.9,1.8,1.7,1.6,1.5,1.4,1.3,1.2,1.1,1,0.9,0.8) .
\end{aligned}
$$

As can be seen in Figure 8, a higher height for placement and picking requires more rest time to prevent ergonomic risks and rest time cost because it may cause a more serious contraction of the muscles when the operator reaches a higher height. Therefore, it increases the need for rest time and the rest time cost as the operator needs to have rest to recover from a longer contraction. We also conducted regression analysis for a better understanding of the relationship between the height of placement for picking and storing and rest time. The regression analysis shows that the relationship between the height of placement for picking of materials $h^{\mathrm{pi}, c}, h^{\mathrm{pi}, s}, h^{\mathrm{pi}, p}$ and rest time is statistically significant based on $p$ value (0.001) and the relationship between the height of placement for storing of materials $h^{\text {st, } c}$, $h^{\text {st, } s}, h^{\text {st, } p}$ and rest time is statistically significant based on a $p$ value (0.001).

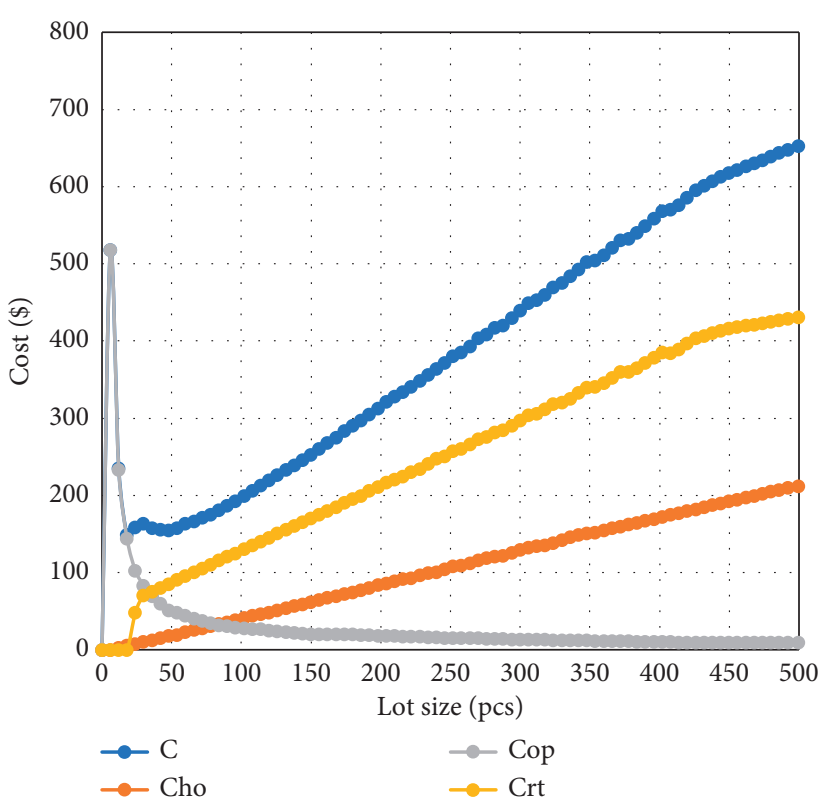

Figure 7: The total cost curve and additional cost curves for the holding cost, the operational cost, and the rest time cost of material one based on different lot sizes where the weights of the items are $0.2 \mathrm{~kg}, 0.3 \mathrm{~kg}$, and $0.4 \mathrm{~kg}$.

Furthermore, we have analyzed the effect of the unit item weight on the lot size of materials. As shown in Figure 9, the increase in the unit weight of the items reduces the optimal lot size values. The optimal lot size values represent the lot sizes where a logistics operator can work continuously and the need for rest time is equal to zero. This means that a lot size higher than the optimal lot size increases the need for rest time and that the logistics operator must have necessary rest time after handling the lot to prevent ergonomic risks due to higher load values. Higher unit item weight increases the contraction of the muscles that leads to increased fatigue and injury risks. Therefore, the model suggests that the lot size needs to be decreased when the item weight increases.

In this analysis, the distance value is considered in different cases, such as the distance between the cart and the production line area is longer or shorter for the analysis of picking and storing (lifting and lowering) motions. The distance values have been changed for $d_{c, p}$ between 2.6 and $0.2 \mathrm{~m}$, and for $d_{c, s}$, they are between 1.4 and $0.2 \mathrm{~m}$. As shown in Figure 10, an increase in the distance between the cart and production area and the distance between the supermarket and the production line causes an increase in the need for rest time and the rest time cost. Furthermore, an increase in the item weight causes an increase in the rest time cost. We also conducted regression analysis for a better understanding of the relationship between the distance between the cart and the supermarket $\left(d_{c, s}\right)$, the distance between the cart and the production line $\left(d_{c, p}\right)$, and rest time. The regression analysis showed the relationships between the distance between the cart and the supermarket $\left(d_{c, s}\right)$ and rest time. 


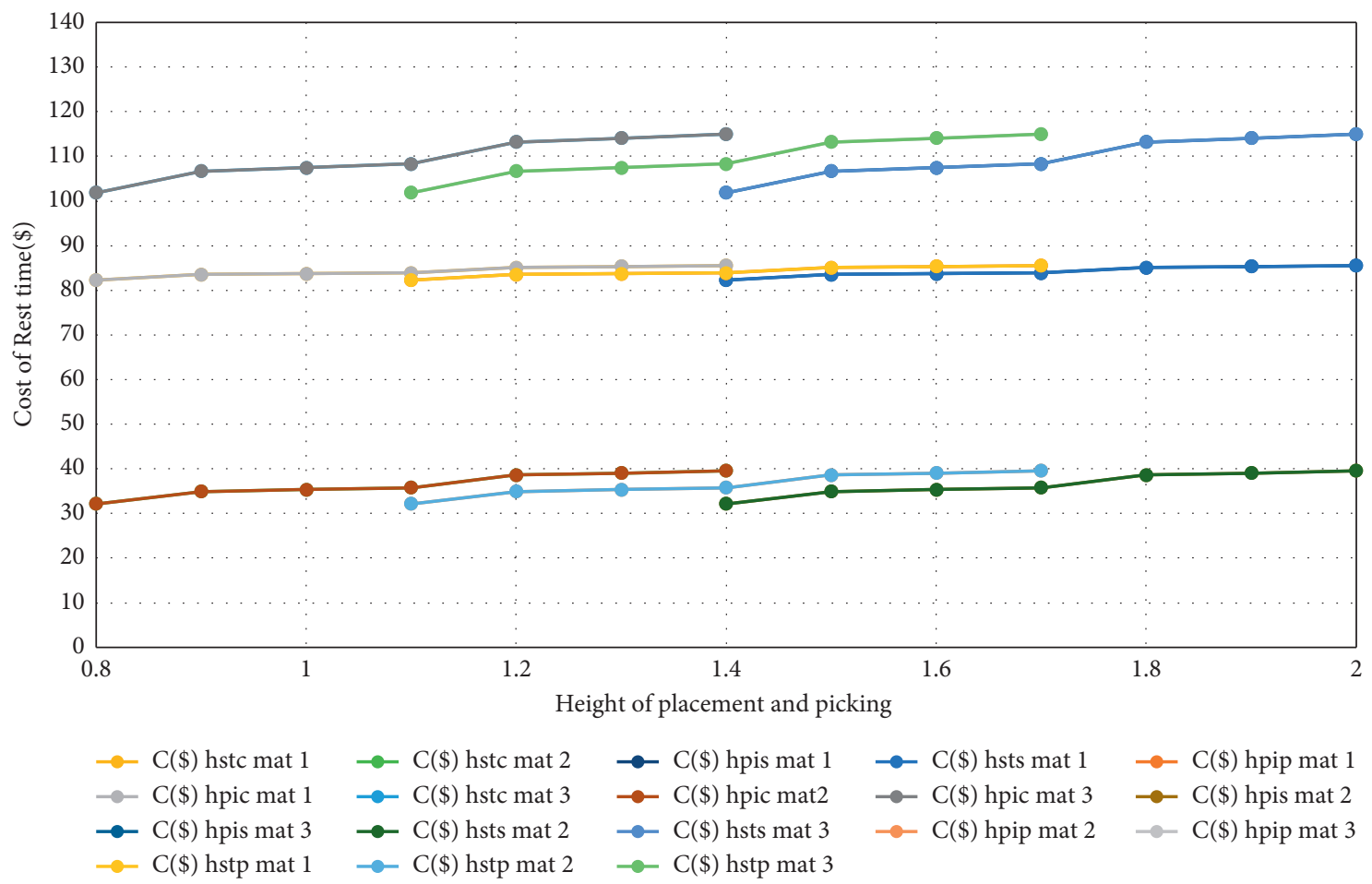

Figure 8: The rest time cost for different heights of placement and picking.

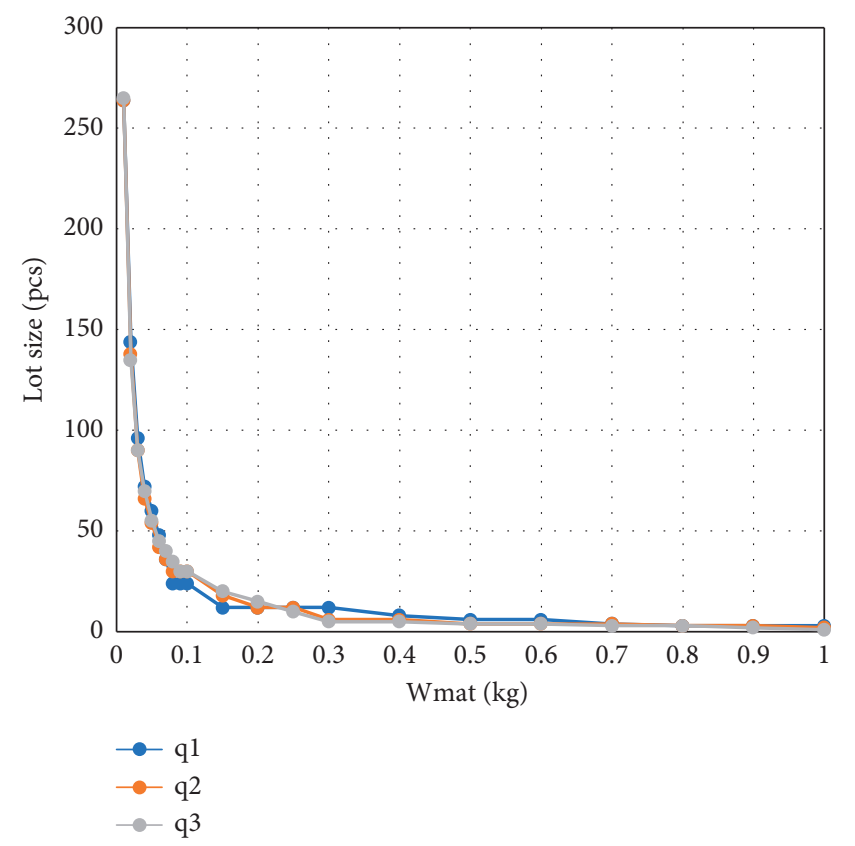

FIGURE 9: Optimal lot sizes $\left(q_{\mathrm{mat}}\right)$ for different weights of each item.

$w_{\text {mat } 1}=0.1 \mathrm{~kg} ; w_{\text {mat } 2}=0.2 \mathrm{~kg} ; w_{\text {mat } 3}=0.3 \mathrm{~kg}$ are statistically significant based on $p$ value $(0.001) ; w_{\text {mat1 }}=0.2 \mathrm{~kg}$; $w_{\text {mat } 2}=0.3 \mathrm{~kg} ; w_{\text {mat3 }}=0.4 \mathrm{~kg}$ are statistically significant based on $p$ value $(0.001)$; and $w_{\text {mat } 1}=0.3 \mathrm{~kg} ; w_{\text {mat } 2}=0.4 \mathrm{~kg}$; $w_{\text {mat } 3}=0.5 \mathrm{~kg}$ are statistically significant based on $p$ value (0.001).
The regression analysis showed the relationships between the distance between the cart and the production line $\left(d_{c, p}\right)$ and rest time.

$w_{\text {mat } 1}=0.1 \mathrm{~kg} ; 0.1 w_{\text {mat } 2}=0.2 \mathrm{~kg} ; w_{\text {mat } 3}=0.3 \mathrm{~kg}$ are statistically significant based on $p$ value $(0.001) ; w_{\text {matl }}=0.2 \mathrm{~kg}$; $w_{\text {mat } 2}=0.3 \mathrm{~kg} ; w_{\text {mat } 3}=0.4 \mathrm{~kg}$ are statistically significant based on $p$ value (0.001); and $w_{\text {mat1 }}=0.3 \mathrm{~kg} ; w_{\text {mat2 }}=0.4 \mathrm{~kg}$; $w_{\text {mat } 3}=0.5 \mathrm{~kg}$ are statistically significant based on $p$ value (0.001).

We applied different distance values to analyze the pushing motion between the supermarket area and the production line area. The distance value of $d_{s, p}$ changes between 300 and $5 \mathrm{~m}$. The unit item weight of the materials has been found as $w_{\text {mat } 1}=0.1 \mathrm{~kg}, w_{\text {mat } 2}=0.2 \mathrm{~kg}$, and $w_{\text {mat } 3}=0.3 \mathrm{~kg}, \quad w_{\text {mat } 1}=0.3 \mathrm{~kg}, \quad w_{\text {mat } 2}=0.4 \mathrm{~kg}, \quad$ and $w_{\text {mat } 3}=0.5 \mathrm{~kg}$, and $w_{\text {mat } 1}=0.4 \mathrm{~kg}, w_{\text {mat } 2}=0.5 \mathrm{~kg}$, and $w_{\text {mat } 3}=0.6 \mathrm{~kg}$.

Figure 11 illustrates that the increase in the distance of $d_{s, p}$ will increase the rest time and the rest time cost. Furthermore, the increase in the distance $d_{s, p}$ will increase the rest time cost more for heavier items. We also conducted regression analysis for a better understanding of the relationship between the distance between the supermarket and the production line $\left(d_{s, p}\right)$ and rest time. The regression analysis showed the relationships between the distance between the supermarket and the production line $\left(d_{s, p}\right)$ and rest time.

$w_{\text {mat } 1}=0.1 \mathrm{~kg} ; w_{\text {mat } 2}=0.2 \mathrm{~kg} ; w_{\text {mat } 3}=0.3 \mathrm{~kg}$ are statistically significant based on $p$ value $(0.001) ; w_{\text {matl }}=0.3 \mathrm{~kg}$; $w_{\text {mat } 2}=0.4 \mathrm{~kg} ; w_{\text {mat } 3}=0.5 \mathrm{~kg}$ are statistically significant based on $p$ value $(0.001)$; and $w_{\text {mat } 1}=0.4 \mathrm{~kg}$; $w_{\text {mat } 2}=0.5 \mathrm{~kg}$; 


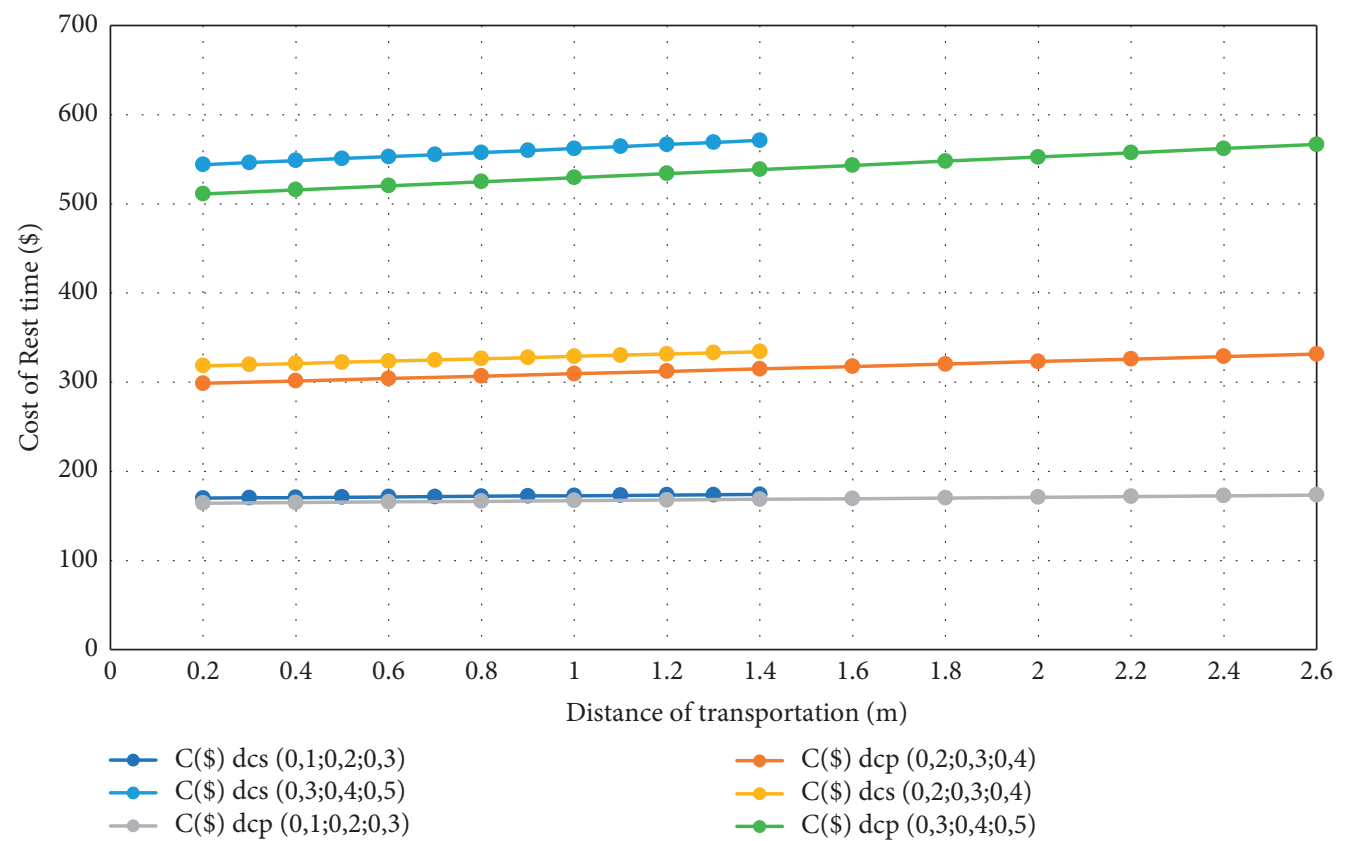

Figure 10: The rest time cost for different distances of transportation $d_{c, s}$ and $d_{c, p}$.

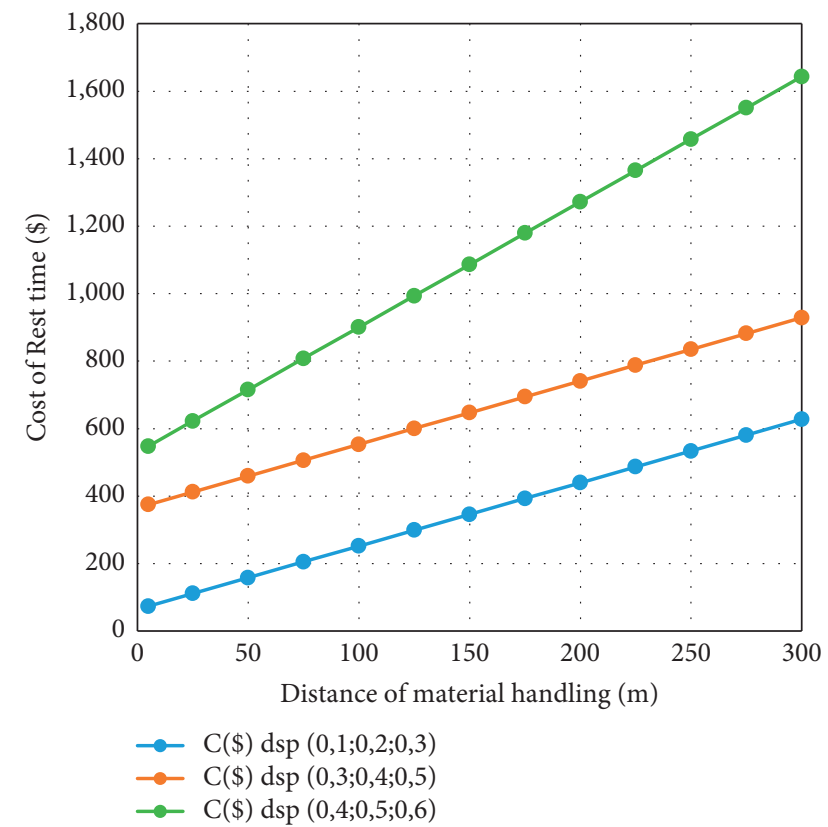

Figure 11: The rest time cost for different distances of material handling.

$w_{\text {mat3 }}=0.6 \mathrm{~kg}$ are statistically significant based on $p$ value (0.001).

5.3. Discussion. Application of the model shows that using the ergonomic rest time and maximum endurance time in this production supply process decreases the total cost of the process with a $13.05 \%$ saving compared to the total cost of the production supply process without the ergonomic rest time and maximum endurance time considerations. The reason is that the ergonomic production supply process model decreases the holding cost and the ergonomic cost of the process. Figure 7 shows the total cost curve and additional cost curves for the holding cost, the operational cost, and the rest time cost of material one based on different lot sizes and weight of the items. The savings and results have been calculated in comparison with the total cost of maximum lifting and carrying limit (25 kg) according to ISO-11228 on Ergonomics-Manual Handling, Part 1: Lifting and Carrying, for two-handed lifting where each lot size is equal to $25 \mathrm{~kg}$. The optimal total cost of our model shows that the savings increases or decreases by increase of unit item weights, especially for materials where the weight is under $0,1 \mathrm{~kg}$ in the production line (see Figure 6). We investigated the different material requirements in the production line (see Table 4), and the results obtained by application of the new model were consistent with the results from saving analysis in case of different materials where the ergonomic production supply process model decreases the holding cost and the ergonomic cost of the process. It has proved that the model developed is decreasing the cost of the production process and it has provided an opportunity to increase the productivity of the workforce by decreasing the ergonomic risks associated with work-related back disorders.

As the optimal lot size analysis shows, the increase in the unit weight of the items reduces the optimal lot size values, where the optimal lot size values represent the value that a logistics operator can work continuously without the need for rest time (see Figure 9). There are two possible solutions during the realization of logistics operations. The first one is the logistics operator can work without rest time needed with the optimal lot size, and the second one is if the lot size is larger than the optimal lot size; therefore, proper rest time must be applied, which the model suggests. This 
TABLE 4: The input parameters of different analyses.

\begin{tabular}{|c|c|c|c|c|c|c|c|c|c|c|c|c|c|}
\hline \multirow{2}{*}{$\begin{array}{l}\text { Parameter } \\
w_{\text {mat1 }}(\mathrm{kg})\end{array}$} & \multirow{2}{*}{$\begin{array}{c}\begin{array}{c}\text { Testing } \\
\text { of the } \\
\text { model }\end{array} \\
0.1\end{array}$} & \multicolumn{3}{|c|}{ Saving analysis } & \multirow{2}{*}{$\begin{array}{l}\text { The cost } \\
\text { analysis }\end{array}$} & \multirow{2}{*}{ 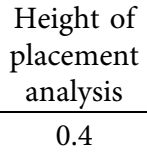 } & \multirow{2}{*}{ 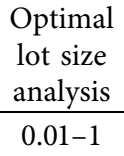 } & \multicolumn{3}{|c|}{$\begin{array}{c}\text { Distance of } \\
\text { transportation analysis }\end{array}$} & \multicolumn{3}{|c|}{$\begin{array}{l}\text { Distance of material } \\
\text { handling analysis }\end{array}$} \\
\hline & & $0.01-3$ & $0.01-3$ & $0.01-3$ & & & & 0.1 & 0.2 & 0.3 & 0.1 & 0.3 & 0.4 \\
\hline$w_{\text {mat2 }}(\mathrm{kg})$ & 0.2 & $0.01-3$ & $0.01-3$ & $0.01-3$ & 0.3 & 0.5 & $0.01-1$ & 0.2 & 0.3 & 0.4 & 0.2 & 0.4 & 0.5 \\
\hline$w_{\text {mat3 }}(\mathrm{kg})$ & 0.3 & $0.01-3$ & $0.01-3$ & $0.01-3$ & 0.4 & 0.6 & $0.01-1$ & 0.3 & 0.4 & 0.5 & 0.3 & 0.5 & 0.6 \\
\hline$w_{\mathrm{ca}}(\mathrm{kg})$ & 15 & 15 & 15 & 15 & 15 & 15 & 15 & 15 & 15 & 15 & 15 & 15 & 15 \\
\hline$w_{\mathrm{em}}(\mathrm{kg})$ & 1 & 1 & 1 & 1 & 1 & 1 & 1 & 1 & 1 & 1 & 1 & 1 & 1 \\
\hline$r_{\text {mat1 }}($ pcs/prod. $)$ & 3 & 5 & 3 & 1 & 1 & 3 & 1 & 1 & 1 & 1 & 1 & 1 & 1 \\
\hline$r_{\text {mat2 }}$ (pcs/prod.) & 2 & 3 & 2 & 1 & 1 & 2 & 1 & 1 & 1 & 1 & 1 & 1 & 1 \\
\hline$r_{\text {mat3 }}$ (pcs/prod.) & 1 & 1 & 1 & 1 & 1 & 1 & 1 & 1 & 1 & 1 & 1 & 1 & 1 \\
\hline$c_{w}(\mathrm{~s} / \mathrm{h})$ & 18 & 18 & 18 & 18 & 18 & 18 & 18 & 18 & 18 & 18 & 18 & 18 & 18 \\
\hline$c_{h, \text { mat } 1}(\mathrm{~s} /(\mathrm{pcs} / \mathrm{h}))$ & 0.02 & 0.02 & 0.02 & 0.02 & 0.04 & 0.02 & 0.02 & 0.02 & 0.02 & 0.02 & 0.02 & 0.02 & 0.02 \\
\hline$c_{h, \text { mat } 2}(\mathrm{~s} /(\mathrm{pcs} / \mathrm{h}))$ & 0.04 & 0.04 & 0.04 & 0.04 & 0.08 & 0.04 & 0.04 & 0.04 & 0.04 & 0.04 & 0.04 & 0.04 & 0.04 \\
\hline$c_{h, \text { mat3 }}(\mathrm{s} /(\mathrm{pcs} / \mathrm{h}))$ & 0.06 & 0.06 & 0.06 & 0.06 & 0.1 & 0.06 & 0.06 & 0.06 & 0.06 & 0.06 & 0.06 & 0.06 & 0.06 \\
\hline$h^{\mathrm{st}, p}(\mathrm{~m})$ & 1.2 & 1.5 & 1.5 & 1.5 & 1.2 & $1.7-0.5$ & 1.2 & 1.2 & 1.2 & 1.2 & 1.2 & 1.2 & 1.2 \\
\hline$h^{\mathrm{pi}, c}(\mathrm{~m})$ & 0.8 & 0.5 & 0.5 & 0.5 & 0.8 & $1.4-0.2$ & 0.8 & 0.8 & 0.8 & 0.8 & 0.8 & 0.8 & 0.8 \\
\hline$h^{\mathrm{pi}, s}(\mathrm{~m})$ & 1.8 & 2 & 2 & 2 & 1.8 & $2-0.8$ & 1.8 & 1.8 & 1.8 & 1.8 & 1.8 & 1.8 & 1.8 \\
\hline$h^{\mathrm{st}, c}(\mathrm{~m})$ & 0.8 & 0.8 & 0.8 & 0.8 & 0.8 & $1.4-0.2$ & 0.8 & 0.8 & 0.8 & 0.8 & 0.8 & 0.8 & 0.8 \\
\hline$h^{\mathrm{pi}, p}(\mathrm{~m})$ & 1.2 & 1.2 & 1.2 & 1.2 & 1.2 & $1.7-0.5$ & 1.2 & 1.2 & 1.2 & 1.2 & 1.2 & 1.2 & 1.2 \\
\hline$h^{\mathrm{st}, s}(\mathrm{~m})$ & 1.8 & 1.8 & 1.8 & 1.8 & 1.8 & $2-0.8$ & 1.8 & 1.8 & 1.8 & 1.8 & 1.8 & 1.8 & 1.8 \\
\hline$d_{c, p}(\mathrm{~m})$ & 0.5 & 0.5 & 0.5 & 0.5 & 0.5 & 0.5 & 0.5 & $2.6-0.2$ & $2.6-0.2$ & $2.6-0.2$ & 0.5 & 0.5 & 0.5 \\
\hline$d_{s, p}(m)$ & 100 & 100 & 100 & 100 & 100 & 100 & 100 & 100 & 100 & 100 & $300-5$ & $300-5$ & $300-5$ \\
\hline$d_{c, s}(\mathrm{~m})$ & 0.5 & 0.5 & 0.5 & 0.5 & 0.5 & 0.5 & 0.5 & $1.4-0.2$ & $1.4-0.2$ & $1.4-0.2$ & 0.5 & 0.5 & 0.5 \\
\hline
\end{tabular}

\begin{tabular}{|c|c|c|c|c|c|c|c|c|}
\hline \multicolumn{9}{|c|}{ Manual material handling (MAMAHA) } \\
\hline \multirow{2}{*}{\multicolumn{2}{|c|}{ Weight of Unit }} & \multirow{3}{*}{$\begin{array}{c}\text { Weight } \\
\text { Code }\end{array}$} & & & & & & \\
\hline From (kg) & & & \multirow{2}{*}{\multicolumn{5}{|c|}{ Time need of move $(10-2 \mathrm{~min} / \mathrm{m})$}} & \\
\hline & 10 (kg) & & & & & & & \\
\hline 0,00 & 2,00 & 1 & 1 & 1,10 & & & & \\
\hline 2,01 & 5,00 & 2 & 2 & 1,40 & & & & \\
\hline 5,01 & 20,00 & 3 & 3 & 1,70 & & & & \\
\hline 20,01 & 50,00 & 4 & 4 & 2,00 & & & & \\
\hline \multicolumn{2}{|c|}{ Height of picking up/storing (m) } & Height & \multicolumn{6}{|c|}{ Time need of picking up (10-2 min) } \\
\hline From $(\mathrm{m})$ & To $(\mathrm{m})$ & Code & & 1 & 2 & 3 & 4 & 5 \\
\hline 0,00 & 0,70 & 1 & 1 & 8 & 10 & 11 & 15 & 16 \\
\hline 0,71 & 1,40 & 2 & 2 & 6 & 8 & 10 & 13 & 14 \\
\hline 1,41 & 2,10 & 3 & 3 & 10 & 12 & 13 & 15 & 17 \\
\hline \multicolumn{2}{|c|}{ Weight of Unit (kg) } & Weight & \multicolumn{6}{|c|}{ Time need of storing (10-2 $\mathrm{min})$} \\
\hline From (kg) & To $(\mathrm{kg})$ & Code & & 1 & 2 & 3 & 4 & 5 \\
\hline 0,00 & 10,00 & 1 & 1 & 6 & 7 & 8 & 11 & 12 \\
\hline 10,01 & 20,00 & 2 & 2 & 4 & 6 & 8 & 9 & 11 \\
\hline 20,01 & 30,00 & 3 & 3 & 8 & 9 & 10 & 11 & 12 \\
\hline 30,01 & 40,00 & 4 & & & & & & \\
\hline 40,01 & 50,00 & 5 & & & & & & \\
\hline
\end{tabular}

FIGURE 12: The time requirements on manual material handling for picking up and storing motions.

means that a lot size higher than the optimal lot size increases the need for rest time and that the logistics operator must have necessary rest time after handling the lot to prevent ergonomic risks due to higher load values. An increase in unit item weight increases the contraction of the muscles that leads to increased fatigue and injury risks. Therefore, the model suggests that the lot size needs to be decreased when the item weight increases to eliminate the ergonomic risks due to load on the spine associated with the work of the logistics operator, which will also prevent the medical costs associated with work-related disorders and injuries.

As the distance of transportation analysis shows, an increase in the distance between the cart and production line $\left(d_{c, p}\right)$ and the distance between the supermarket and the cart $\left(d_{c, s}\right)$ causes an increase in the need for rest time and the rest time cost (see Figure 10). Furthermore, an increase in the item weight causes an increase in the rest time cost and rest 


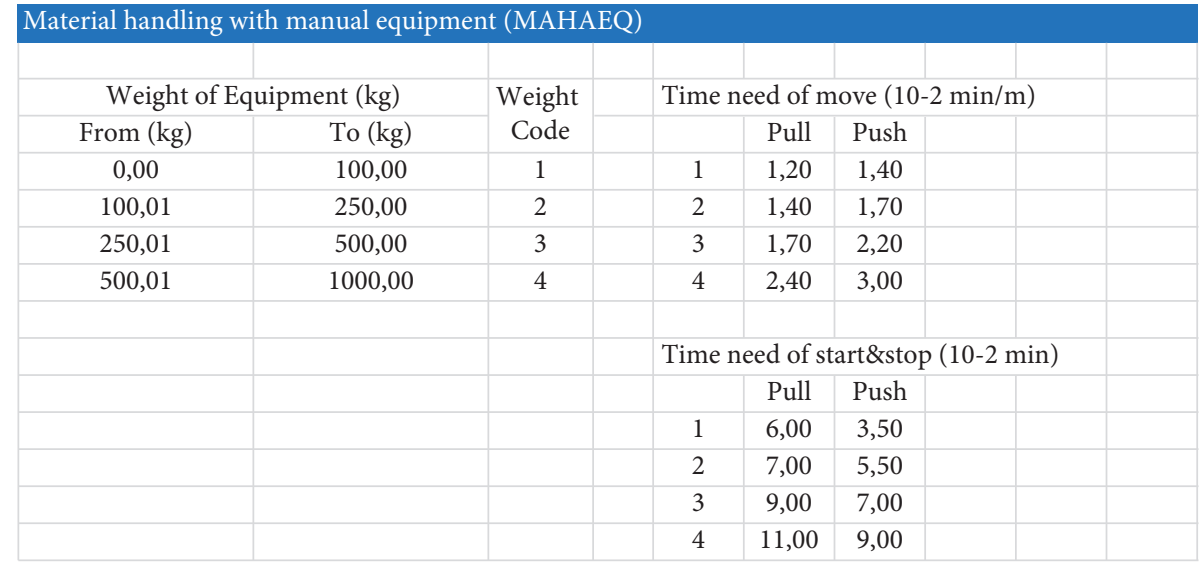

Figure 13: The time requirements on manual material handling for pulling and pushing motions.

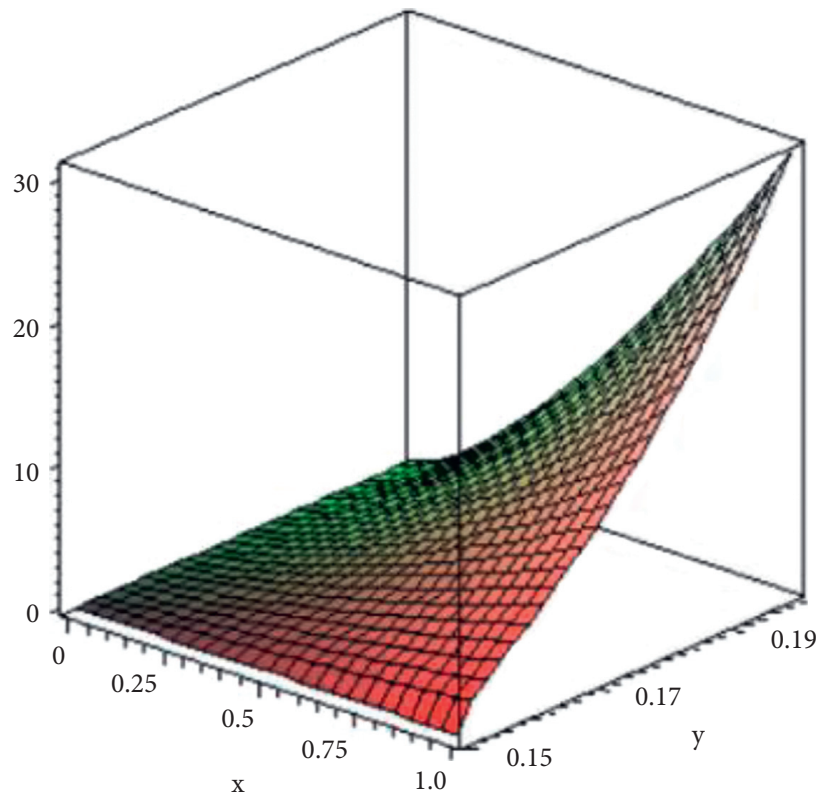

FIgURE 14: The $\operatorname{RT}(x, y)$ function.

time need of an operator. This is because the increase in item weight increases the contraction of the muscles that leads to a higher injury risk. Simultaneously, the analysis related to the distance of material handling shows that the increase in the distance between the supermarket and the production line $\left(d_{s, p}\right)$ will increase the rest time and the rest time cost (see Figure 11). Furthermore, the increase in this distance will increase the rest time cost more for heavier items. These analyses could help managers to evaluate different lot sizes according to the distance of transportation and distance of material handling to prevent the ergonomic risks due to long contraction time. It is important to highlight that this method can help in the efficient design of the processes, which decreases the ergonomic risk associated with the distance of transportation and material handling.

According to the height of placement analysis, a higher height for placement-where $h^{\text {st, } p}$ represents the height of placement of the production line for storing, $h^{\text {st, } c}$ represents the height of placement of the cart for storing, $h^{\text {st,s }}$ represents the height of placement of the supermarket for storing, where $h^{\mathrm{pi}, c}$ represents the height of placement of the cart for picking, $h^{\mathrm{pi}, s}$ represents the height of placement of the supermarket for picking, and $h^{\mathrm{pi}, p}$ represents the height of placement of the production line for picking-requires more rest time to prevent ergonomic risks because it may cause a more serious contraction of the muscles when the operator reaches a higher height. Furthermore, the increase of height increases the need for rest time, and it leads to more rest time cost because the operator needs to have rest to recover from a longer contraction. As a result, it can be said that the consideration of this effect can help in the process design to prevent the ergonomic risks associated with the height of placement of materials for improving the worker's health and productivity.

The results of the analyses show that the model, despite its limitations, constitutes a useful guide for the search for the optimum lot sizes for the production line supply process 


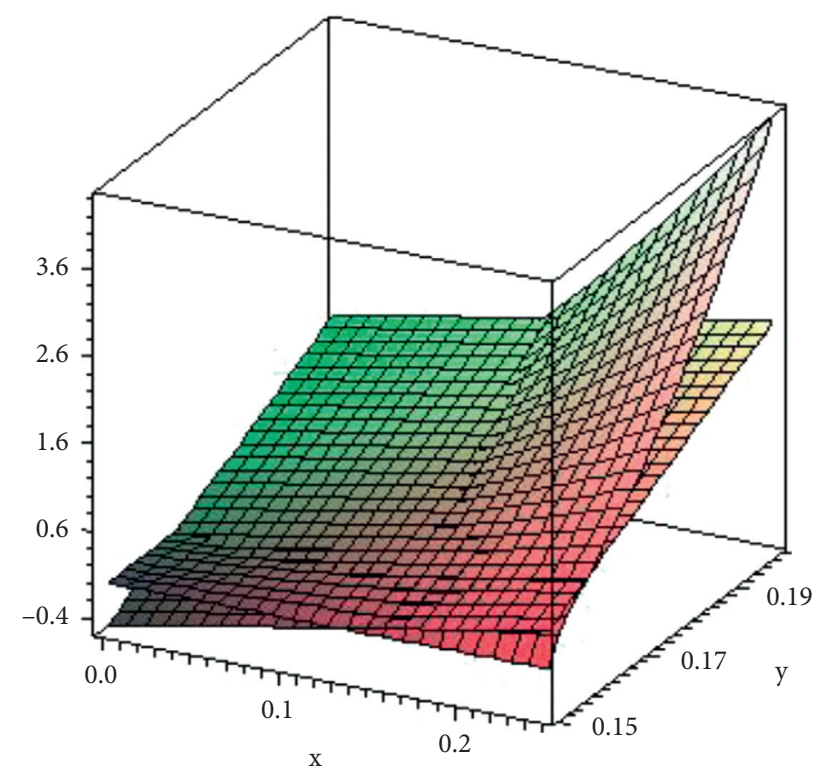

Figure 15: The $\operatorname{RT}(x, y)$ and $Z(x, y)$ functions.

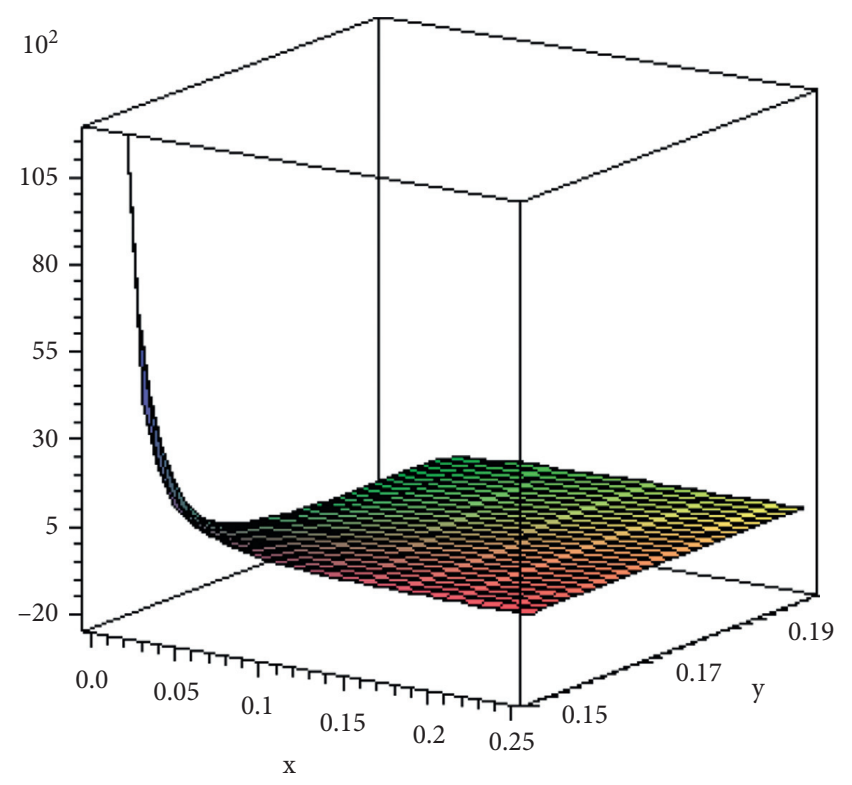

FIGURE 16: The error function.

of multi-materials. It improves both social sustainability as it prevents ergonomic risks and economic sustainability as it increases the productivity of the operator, decreases the medical cost associated with work-related back disorders, and decreases the total cost of the process.

5.4. Limitations of the Study. In this study, there is a limitation that can be addressed in future research. The study focuses on an average person as a worker for the calculation of rest allowance and maximum endurance time. However, several other factors associated with human performance and health can also have an impact on the rest time needs and maximum endurance time, and they should be addressed in future studies. Further research can investigate human diversity, such as age, gender, and health condition of the worker for the calculation of rest time and maximum endurance time. Besides, the study focused mainly on motions directly associated with the execution of the production line supply tasks by the workers that are picking, storing, and pushing. However, the other motions such as pulling and carrying can also have an impact on human performance and health, and they should be addressed in future studies.

\section{Conclusion}

Inventory management and lot sizing play a critical role in business success. Various kinds of research have been done to find the optimum plan or lot size to reach sustainable success. Especially, economic and environmental sustainability aspects have been investigated extensively and integrated by many researchers. However, there are only a few contributions regarding human health and social sustainability. This paper demonstrates an extended economic and ergonomic multi-material inventory model to investigate this research gap. The model developed integrates the rest allowance to reduce ergonomic risks and work-related disorders of the back. The rest allowance is determined by endurance time, contraction time, and relative force based on the weight and number of the items. The rest time is the time required to prevent the risks of fatigue associated with a load value higher than the optimal lot size. The new model aims to minimize both the total cost of the production line supply process and ergonomic risks. The case study based on our model presented in this paper investigates the supply of three different raw materials with one operator to the production line with a simple cart as a single-operatormulti-material model. The efficiency of the model has been investigated with the simulation and parameteric analysis through different datasets. The analyses have proved that the 
model developed is suitable for different practices, with the constituted rest time provided with an opportunity to increase the productivity of the workforce and to reduce the cost of a company. Furthermore, the analyses have shown that a higher distance of movement and height of placement for manual material handling will cause a higher need for rest time. The relevant approach can help managers to evaluate lot sizes with the distance of movement (production line and supermarket) and the height of placement and the effects of picking to prevent ergonomic risks. In addition, it will decrease high costs for work-related musculoskeletal disorders, work-related disorders of the back, absenteeism, productivity loss, increased health care, disabilities, and workers' compensation costs. Our model also can help managers to maintain the decision-making process based on a schedule of work-rest time. The results of this study have demonstrated the viability of the inventory model optimization with multiple objectives and complex constraints. With regard to the maximum endurance time, the pushing motion and the multi-material production line supply in an inventory model have been considered for the first time. Most notably, this study helps to interpret the optimal ergonomic lot size by using special aspects for multi-materials that accommodate social and economic sustainability in the production line supply.

Furthermore, future research can investigate a scenario handling many materials by multi-operator (MMMO) and single material by multi-operator (SMMO) for a better understanding of the relationship between lot sizing and ergonomics in the production line supply and can investigate how to improve the ergonomic and economic conditions in industrial practices. In addition, future research can investigate a lot-sizing model with ergonomics for different manual material handling tasks, and it would be valuable to extend this study with the integration of other motions such as carrying and pulling.

\section{Appendix}

\section{A. Calculation of the Time Needs of the Movements with the AIM Tables}

We applied the AIM tables to calculate the time needs of movements. The time requirements on manual material handling for picking up and storing motions can be seen in Figure 12. Based on Figure 12, first, we have found the time need of movement based on the code value $\left(10^{-2} \mathrm{~min} / \mathrm{m}\right)$ for picking up and storing motions based on the unit weight $\left(w_{\text {mat }}^{\text {uni }}\right)$ and multiplied it with the distance of movement $d$ (m). Second, we have found the time need of picking up based on the height code $\left(h^{\mathrm{pi}}\right)$ and the weight code $\left(w_{\text {mat }}^{\text {uni }}\right)$. Third, we have found the time need of storing based on the height code $\left(h^{\text {st }}\right)$ and the weight code of picking-storing $\left(w_{\text {mat }}^{\text {uni }}\right)$. Finally, we have summed the time need values of the movement and picking up for the calculation of the time needs of picking up, the time need of the movement value, and the time needs of storing.

The time requirements on manual material handling for pulling and pushing motions can be seen in Figure 13. We have calculated the time need of movement based on the code value $\left(10^{-2} \mathrm{~min} / \mathrm{m}\right)$ for pushing motion based on the total weight of the loaded equipment $\left(w_{\mathrm{ca}}+\sum_{\mathrm{mat}=1}^{M} x_{\mathrm{mat}, t} \cdot w_{\mathrm{mat}}^{\mathrm{uni}}\right)$ and multiplied it with distance of movement " $d$ " for pushing $(\mathrm{m})$. Then, we have found the time need of start and stop according to the weight code $\left(w_{\mathrm{ca}}+\sum_{\mathrm{mat}=1}^{M} x_{\mathrm{mat}, t} \cdot w_{\mathrm{mat}}^{\mathrm{uni}}\right)$. Finally, we have summed the time need values of the movement and start and stop pushing to find the time need of pushing motions. Furthermore, we have applied the same steps for the calculation of the time need for pushing back except finding the weight code based on $\left(w_{\mathrm{ca}}+\sum_{\mathrm{em}=1}^{E} x_{\mathrm{em}, t} \cdot w_{\mathrm{em}}\right)$.

\section{B. Representation of the Linearization of Maximum Endurance Time and Rest Time Equations Presented by Rohmert}

We applied the tangent plane approximation to the exponential rest time and maximum endurance time functions introduced by Rohmert $[25,26]$ for the expression of the linear form. Maximum endurance time and rest time equations can be defined as follows $[25,26]$ :

$$
\mathrm{RT}=1800 \cdot\left(\frac{t}{T_{E}}\right)^{1,4} \cdot(\mathrm{fMVC}-0,15)^{0,5}, \quad \text { where } T_{E}=-1,5+\frac{2,1}{\mathrm{fMVC}}-\frac{0,6}{\mathrm{fMVC}^{2}}+\frac{0,1}{\mathrm{fMVC}^{3}}
$$


As shown in Figure 14, we can describe the $\operatorname{RT}(x, y)$ function as follows:

$$
\mathrm{RT}=1800 \cdot\left(\frac{x}{-1,5+((2,1) / y)-\left((0,6) / y^{2}\right)+\left((0,1) / y^{3}\right)}\right)^{1,4} \cdot(y-0,15)^{0,5}
$$

where $t=x ; \mathrm{fMVC}=y$; and $y \geq 0.15$.

We applied the datasets to the $\operatorname{RT}(x, y)$ function as follows: $x=0, \ldots, 1$, and $y=0.15 \ldots 0.20$.

We have used the general equation of a plane to determine the equation of the tangent plane $Z(x, y) . Z(x, y)$ as follows:

$$
\begin{aligned}
Z(x, y)= & \operatorname{RT}\left(x_{0}, y_{0}\right)+\frac{\mathrm{d}}{\mathrm{d} x} \operatorname{RT}\left(x_{0}, y_{0}\right) \cdot\left(x-x_{0}\right) \\
& +\frac{\mathrm{d}}{\mathrm{d} y} \operatorname{RT}\left(x_{0}, y_{0}\right) \cdot\left(y-y_{0}\right),
\end{aligned}
$$

where $x_{0}=0.16, y_{0}=0.16$.

Furthermore, we have decided to use these points according to the optimum points area of the $\operatorname{RT}(x, y)$ function (see Figure 14). As shown in Figure 15, the $Z(x, y)$ tangent plane function just touches the surface $\mathrm{RT}(x, y)$ function at the point $\left(x_{0}, y_{0}\right)$. The calculation of the approximate surface $Z(x, y)$ near the points $\left(x_{0}=0,16, y_{0}=\right.$ $0,16)$ is as follows:

$$
\begin{aligned}
\frac{\mathrm{d}}{\mathrm{d} x} \mathrm{RT}= & \frac{2632 \cdot\left(x /\left(-1,5+((2,1) / y)-\left((0,6) / y^{2}\right)+\left((0,1) / y^{3}\right)\right)\right)^{0,4} \cdot(y-0,15)^{0,5}}{-1,5+((2,1) / y)-\left((0,6) / y^{2}\right)+\left((0,1) / y^{3}\right)}, \\
\frac{\mathrm{d}}{\mathrm{d} y} \mathrm{RT}= & -2632 \cdot \frac{\left(x /\left(-1,5+((2,1) / y)-\left((0,6) / y^{2}\right)+\left((0,1) / y^{3}\right)\right)\right)^{0,4} \cdot(y-0,15)^{0,5} \cdot x\left(-2,1\left(1 / y^{2}\right)+\left((1,2) / y^{3}\right)-\left((0,3) / y^{4}\right)\right)}{\left.(-1,5+((2,1) / y))-\left((0,6) / y^{2}\right)+\left((0,1) / y^{3}\right)\right)^{2}} \\
& +\frac{940 \cdot\left(x /\left(-1,5+((2,1) / y)-\left((0,6) / y^{2}\right)+\left((0,1) / y^{3}\right)\right)\right)^{1,4}}{(y-0,15)^{0,5}}
\end{aligned}
$$

where

$$
\begin{aligned}
\operatorname{RT}\left(x_{0}, y_{0}\right) & =0,4162283603 \\
\frac{\mathrm{d}}{\mathrm{d} x} \operatorname{RT}\left(x_{0}, y_{0}\right) & =3,641998153 \\
\frac{\mathrm{d}}{\mathrm{d} y} \operatorname{RT}\left(x_{0}, y_{0}\right) & =32,22511961
\end{aligned}
$$

$$
\begin{aligned}
Z(x, y) & =0,4162+3,6419 \cdot\left(x-x_{0}\right)+32,2251 \cdot\left(y-y_{0}\right), \\
\operatorname{RT}(x, y) & \approx Z(x, y)=3.6419 \cdot t+(32.2251 \cdot \mathrm{fMVC})-5.3225
\end{aligned}
$$

We have calculated the percentage error of the approximation as follows:

$$
\text { Error }[\%]=\frac{100 \cdot|\mathrm{RT}(x, y)-Z(x, y)|}{\mathrm{RT}(x, y)} \leq 5[\%] \text {. }
$$

The percentage error for $\left(x_{0}, y_{0}\right)$ points is equal to $4.2 \%$, which is acceptable as it is lower than $5 \%$. As can be seen in Figure 16, we have calculated the percentage error for the dataset with equation (B.7), and the percentage errors are lower than $5 \%$. 


\section{Data Availability}

The data used to support the findings of this study are available from the corresponding author upon request.

\section{Conflicts of Interest}

The authors declare that they have no conflicts of interest.

\section{Acknowledgments}

This study was supported by the Tempus Public Foundation as part of the Ph.D. Research Program.

\section{References}

[1] F. W. Harris, "Reports and proceedings," Geological Magazine, vol. 10, no. 3, pp. 135-138, 1913.

[2] A. Andriolo, D. Battini, R. W. Grubbström, A. Persona, and F. Sgarbossa, "A century of evolution from Harris's basic lot size model: survey and research agenda," International Journal of Production Economics, vol. 155, pp. 16-38, 2014.

[3] H. Badri Ahmadi, S. Kusi-Sarpong, and J. Rezaei, "Assessing the social sustainability of supply chains using best worst method," Resources, Conservation and Recycling, vol. 126, pp. 99-106, 2017.

[4] F. Ciccullo, M. Pero, M. Caridi, J. Gosling, and L. Purvis, "Integrating the environmental and social sustainability pillars into the lean and agile supply chain management paradigms: a literature review and future research directions," Journal of Cleaner Production, vol. 172, pp. 2336-2350, 2018.

[5] N. Kazemi, S. H. Abdul-Rashid, R. A. R. Ghazilla, E. Shekarian, and S. Zanoni, "Economic order quantity models for items with imperfect quality and emission considerations," International Journal of Systems Science: Operations \& Logistics, vol. 5, no. 2, pp. 99-115, 2018.

[6] O. Al-Araidah, G. Okudan-Kremer, E. E. Gunay, and C.-Y. Chu, "A Monte Carlo simulation to estimate fatigue allowance for female order pickers in high traffic manual picking systems," International Journal of Production Research, vol. 59, no. 15, pp. 4711-4722, 2020.

[7] A. Andriolo, D. Battini, A. Persona, and F. Sgarbossa, "A new bi-objective approach for including ergonomic principles into EOQ model," International Journal of Production Research, vol. 54, no. 9, pp. 2610-2627, 2016.

[8] D. Battini, M. Faccio, A. Persona, and F. Sgarbossa, "New methodological framework to improve productivity and ergonomics in assembly system design," International Journal of Industrial Ergonomics, vol. 41, no. 1, pp. 30-42, 2011.

[9] D. Battini, C. Martina, P. Alessandro, and S. Fabio, "Linking human availability and ergonomics parameters in orderpicking systems," IFAC-PapersOnLine, vol. 48, no. 3, pp. 345-350, 2015.

[10] D. Battini, C. H. Glock, E. H. Grosse, A. Persona, and F. Sgarbossa, "Ergo-lot-sizing: considering ergonomics in lotsizing decisions," IFAC-PapersOnline, vol. 48, no. 3, pp. 326-331, 2015.

[11] D. Battini, M. Calzavara, A. Otto, and F. Sgarbossa, "The integrated assembly line balancing and parts feeding problem with ergonomics considerations," IFAC-PapersOnLine, vol. 49, no. 12, pp. 191-196, 2016 a.

[12] D. Battini, M. Calzavara, A. Otto, and F. Sgarbossa, "Preventing ergonomic risks with integrated planning on assembly line balancing and parts feeding," International
Journal of Production Research, vol. 55, no. 24, pp. 7452-7472, 2017.

[13] D. Battini, C. H. Glock, E. H. Grosse, A. Persona, and F. Sgarbossa, "Ergo-lot-sizing: an approach to integrate ergonomic and economic objectives in manual materials handling," International Journal of Production Economics, vol. 185, pp. 230-239, 2017.

[14] L. Botti, C. Mora, and A. Regattieri, "Integrating ergonomics and lean manufacturing principles in a hybrid assembly line," Computers \& Industrial Engineering, vol. 111, pp. 481-491, 2017.

[15] S. Finco, D. Battini, X. Delorme, A. Persona, and F. Sgarbossa, "Heuristic methods to consider rest allowance into assembly balancing problem," IFAC-PapersOnLine, vol. 51, no. 11, pp. 669-674, 2018.

[16] S. Finco, D. Battini, X. Delorme, A. Persona, and F. Sgarbossa, "Workers' rest allowance and smoothing of the workload in assembly lines," International Journal of Production Research, vol. 58, no. 4, pp. 1255-1270, 2020.

[17] S. Finco, M.-A. Abdous, M. Calzavara, D. Battini, and X. Delorme, "A bi-objective model to include workers' vibration exposure in assembly line design," International Journal of Production Research, vol. 59, no. 13, pp. 4017-4032, 2020.

[18] M. A. Zadjafar and M. R. Gholamian, "A sustainable inventory model by considering environmental ergonomics and environmental pollution, case study: pulp and paper mills," Journal of Cleaner Production, vol. 199, pp. 444-458, 2018.

[19] Z. Zhang, Q. Tang, R. Ruiz, and L. Zhang, "Ergonomic risk and cycle time minimization for the $\mathrm{U}$-shaped worker assignment assembly line balancing problem: a multi-objective approach," Computers \& Operations Research, vol. 118, Article ID 104905, 2020.

[20] R. S. Panush, "Occupational and recreational musculoskeletal disorders," Kelley and Firestein's Textbook of Rheumatology, Elsevier, Amsterdam, Netherlands, pp. 520-532, 2017.

[21] EU-OSHA, "Research on work-related low back disorders," 2000, https://osha.europa.eu/en/tools-and-publications/ publications/reports/204.

[22] T. Driscoll, G. Jacklyn, J. Orchard et al., "The global burden of occupationally related low back pain: estimates from the global burden of disease 2010 study," Annals of the Rheumatic Diseases, vol. 73, no. 6, pp. 975-981, 2014.

[23] EU-OSHA, "An international comparison of the cost of workrelated accidents and illnesses,” 2017, https://osha.europa.eu/ en/tools-and-publications/publications/internationalcomparison-cost-work-related-accidents-and/view.

[24] S. Bevan, "Economic impact of musculoskeletal disorders (MSDs) on work in Europe," Best Practice \& Research Clinical Rheumatology, vol. 29, no. 3, pp. 356-373, 2015.

[25] W. Rohmert, "Ermittlung von Erholungspausen für statische Arbeit des Menschen," Internationale Zeitschrift für Angewandte Physiologie Einschliesslich Arbeitsphysiologie, vol. 18, no. 2, pp. 123-164, 1960.

[26] W. Rohmert, "Problems in determining rest allowances," Applied Ergonomics, vol. 4, no. 2, pp. 91-95, 1973.

[27] S. Tiwari, Y. Daryanto, and H. M. Wee, "Sustainable inventory management with deteriorating and imperfect quality items considering carbon emission," Journal of Cleaner Production, vol. 192, pp. 281-292, 2018.

[28] E. W. Taft, "The most economical production lot," Iron Age, vol. 101, pp. 1410-1412, 1918. 
[29] H. M. Wagner and T. M. Whitin, "Dynamic version of the economic lot size model," Management Science, vol. 5, no. 1, pp. 89-96, 1958.

[30] P. Ghare and G. Schrader, "A model for exponentially decaying inventory system," International Journal of Production Research, vol. 21, pp. 449-460, 1963.

[31] S. Goyal, "Economic order quantity under conditions of permissible delay in payments," Journal of the Operational Research Society, vol. 36, pp. 35-38, 1985.

[32] G. Hadley and T. Whitin, Analysis of Inventory Systems, Prentice-Hall, Hoboken, NJ, USA, 1963.

[33] J. Rezaei, "Economic order quantity for growing items," International Journal of Production Economics, vol. 155, pp. 109-113, 2014.

[34] C.-T. Chang, M.-C. Cheng, and P.-Y. Soong, "Impacts of inspection errors and trade credits on the economic order quantity model for items with imperfect quality," International Journal of Systems Science: Operations \& Logistics, vol. 3, no. 1, pp. 34-48, 2016.

[35] L. R. A. Cunha, A. P. S. Delfino, K. A. dos Reis, and A. Leiras, "Economic production quantity (EPQ) model with partial backordering and a discount for imperfect quality batches," International Journal of Production Research, vol. 56, no. 18, pp. 6279-6293, 2018.

[36] M. K. Salameh and M. Y. Jaber, "Economic production quantity model for items with imperfect quality," International Journal of Production Economics, vol. 64, no. 1-3, pp. 59-64, 2000.

[37] M. Sebatjane and O. Adetunji, "Economic order quantity model for growing items with incremental quantity discounts," Journal of Industrial Engineering International, vol. 15, no. 4, pp. 545-556, 2019.

[38] M. Safaeian, A. M. Fathollahi-Fard, G. Tian, Z. Li, and H. Ke, "A multi-objective supplier selection and order allocation through incremental discount in a fuzzy environment," Journal of Intelligent and Fuzzy Systems, vol. 37, no. 1, pp. 1435-1455, 2019.

[39] G. Ahmadi, S. A. Torabi, and R. Tavakkoli-Moghaddam, "A bi-objective location-inventory model with capacitated transportation and lateral transshipments," International Journal of Production Research, vol. 54, no. 7, pp. 2035-2056, 2016.

[40] I. Darma Wangsa and H. M. Wee, "An integrated vendorbuyer inventory model with transportation cost and stochastic demand," International Journal of Systems Science: Operations \& Logistics, vol. 5, no. 4, pp. 295-309, 2018.

[41] Q.-H. Zhao, S.-Y. Wang, K.-K. Lai, and G.-P. Xia, "Model and algorithm of an inventory problem with the consideration of transportation cost," Computers \& Industrial Engineering, vol. 46, no. 2, pp. 389-397, 2004.

[42] M. C. Arslan and M. Turkay, "EOQ revisited with sustainability considerations," Foundations of Computing and Decision Sciences, vol. 38, no. 4, pp. 223-249, 2013.

[43] D. Battini, A. Persona, and F. Sgarbossa, "A sustainable EOQ model: theoretical formulation and applications," International Journal of Production Economics, vol. 149, pp. 145-153, 2014a.

[44] Y. Bouchery, A. Ghaffari, Z. Jemai, and Y. Dallery, "Including sustainability criteria into inventory models," European Journal of Operational Research, vol. 222, no. 2, pp. 229-240, 2012.

[45] N. A. Darom, H. Hishamuddin, R. Ramli, and Z. Mat Nopiah, "An inventory model of supply chain disruption recovery with safety stock and carbon emission consideration," Journal of Cleaner Production, vol. 197, pp. 1011-1021, 2018.

[46] P. He, W. Zhang, X. Xu, and Y. Bian, "Production lot-sizing and carbon emissions under cap-and-trade and carbon tax regulations," Journal of Cleaner Production, vol. 103, no. 9, pp. 241-248, 2015.

[47] M. Y. Jaber, C. H. Glock, and A. M. A. El Saadany, "Supply chain coordination with emissions reduction incentives," International Journal of Production Research, vol. 51, no. 1, pp. 69-82, 2013.

[48] C. H. Glock, M. Y. Jaber, and C. Searcy, "Sustainability strategies in an EPQ model with price- and quality-sensitive demand," International Journal of Logistics Management, vol. 23, no. 3, pp. 340-359, 2012.

[49] M. I. M. Wahab, S. M. H. Mamun, and P. Ongkunaruk, "EOQ models for a coordinated two-level international supply chain considering imperfect items and environmental impact," International Journal of Production Economics, vol. 134, no. 1, pp. 151-158, 2011.

[50] S. Korkulu and K. Bóna, "Ergonomics as a social component of sustainable lot-sizing: a review," Periodica Polytechnica, Social and Management Sciences, vol. 27, no. 1, pp. 1-8, 2019.

[51] J. Z. P. Gacesa, A. V. Klasnja, and N. G. Grujic, "Changes in strength, endurance, and fatigue during a resistance-training program for the triceps Brachii muscle," Journal of Athletic Training, vol. 48, no. 6, pp. 804-809, 2013.

[52] H. Monod and J. Scherrer, "The work capacity of a synergic muscular group," Ergonomics, vol. 8, no. 3, pp. 329-338, 1965.

[53] H. Sato, J. Ohashi, K. Iwanaga, R. Yoshitake, and K. Shimada, "The occupational ergonomics handbook: endurance time and fatigue in static contractions," Journal of Human Ergology, vol. 13, no. 2, pp. 147-154, 1984.

[54] W. Rohmert, M. Wangenheim, J. Mainzer, P. Zipp, and W. Lesser, "A study stressing the need for a static postural force model for work analysis," Ergonomics, vol. 29, no. 10, pp. 1235-1249, 1986.

[55] G. Sjogaard, "The ergonomics of working postures: intramuscular changes during long-term contraction," 1986.

[56] I. Manenica, The Ergonomics of Working Postures: A Technique for Postural Load Assessment, pp. 270-277, Taylor and Francis, London, UK, 1986.

[57] L. Rose, R. Örtengren, and M. Ericson, "Endurance, pain and resumption in fully flexed postures," Applied Ergonomics, vol. 32, no. 5, pp. 501-508, 2001.

[58] A. Garg, D. B. Chaffin, and G. D. Herrin, "Prediction of metabolic rates for manual materials handling jobs," American Industrial Hygiene Association Journal, vol. 39, no. 8, pp. 661-674, 1978.

[59] E.-P. Takala, I. Pehkonen, M. Forsman et al., "Systematic evaluation of observational methods assessing biomechanical exposures at work," Scandinavian Journal of Work, Environment \& Health, vol. 36, no. 1, pp. 3-24, 2010.

[60] T. R. Waters, M.-L. Lu, L. A. Piacitelli, D. Werren, and J. A. Deddens, "Efficacy of the revised NIOSH lifting equation to predict risk of low back pain due to manual lifting," Journal of Occupational and Environmental Medicine, vol. 53, no. 9, pp. 1061-1067, 2011.

[61] K. El ahrache, D. Imbeau, and B. Farbos, "Percentile values for determining maximum endurance times for static muscular work," International Journal of Industrial Ergonomics, vol. 36, no. 2, pp. 99-108, 2006.

[62] A. D. F. Price, "Calculating relaxation allowances for construction operatives. Part 1: metabolic cost," Applied Ergonomics, vol. 21, no. 4, pp. 311-317, 1990. 
[63] Z. Barta and K. Bona, "Development of AIM method planning of inbound material handling processess," Acta Technica Jaurinensis Series Logistica, vol. 3, no. 3, pp. 285-299, 2010, https://acta.sze.hu/index.php/acta/article/view/79.

[64] H. Seidel, H. Beyer, and D. Bräuer, "Electromyographic evaluation of back muscle fatigue with repeated sustained contractions of different strengths," European Journal of Applied Physiology and Occupational Physiology, vol. 56, no. 5, pp. 592-602, 1987.

[65] J. P. Callaghan and S. M. McGill, "Intervertebral disc herniation: studies on a porcine model exposed to highly repetitive flexion/extension motion with compressive force," Clinical Biomechanics, vol. 16, no. 1, pp. 28-37, 2001.

[66] K. P. Granata, G. P. Slota, and S. E. Wilson, "Influence of fatigue in neuromuscular control of spinal stability," Human Factors: The Journal of the Human Factors and Ergonomics Society, vol. 46, no. 1, pp. 81-91, 2004.

[67] ISO 11228-1, "Ergonomics-manual handling-part 1: lifting and carrying," 2003, https://www.iso.org/obp/ui/\#iso:std:iso: 11228:-1:ed-1:v1:en.

[68] M. L. Resnick and D. B. Chaffin, "An ergonomic evaluation of handle height and load in maximal and submaximal cart pushing," Applied Ergonomics, vol. 26, no. 3, pp. 173-178, 1995.

[69] Ministry of Labor and Social Security of Turkey, "Work related musculoskeletal disorders. Occupational health and safety journal," 2007, https://www.csgb.gov.tr/media/4054/34. pdf. 